\title{
Are the Modern Drought Management Plans Modern Enough? The Guadalquivir River Basin Case in Spain
}

\author{
Carmen Hervás-Gámez ${ }^{1, *(1)}$ and Fernando Delgado-Ramos ${ }^{2}$ (1) \\ 1 Department of Structural Mechanics and Hydraulic Engineering, ETSI Caminos, Canales y Puertos, \\ University of Granada, 18001 Granada, Spain \\ 2 Institute of Water Research, Department of Structural Mechanics and Hydraulic Engineering, University of \\ Granada, 18001 Granada, Spain; fdelgado@ugr.es \\ * Correspondence: karmina.doctorado@gmail.com
}

Received: 19 November 2019; Accepted: 18 December 2019; Published: 21 December 2019

\begin{abstract}
Droughts and water scarcity events are predicted to be more frequent and intense in the future, especially in Mediterranean countries. However, are the most recent drought management plans (DMPs) built on the latest technical, engineering, and scientific knowledge, as well as the learning experiences from managing historical droughts? The most significant challenge that surfaces, when a new drought event strikes, is the difficulty in predicting its duration (which can vary from months to years), the severity (or degree of affection to water resources), and the potential environmental, economic, and social impacts. Hence, there is an importance of integrating reliable forecasting and modeling tools in the development of modern DMPs, so the potential risk can be assessed under a range of possible drought scenarios. This will ensure that the proposed measures and actions of the DMP are sufficiently robust and proportionate to the drought and water scarcity situation. This paper provides a critical assessment of the core technical concepts and principles to be taken into consideration when developing the methodological and operational framework of a DMP. The case of study chosen is the Guadalquivir River Basin in southern Spain, which presents one of the most complex and paradigmatic cases in this regard. This region suffers recurrent episodes of drought and water scarcity, together with fierce competition among water users. Recently, a new strategic DMP has been approved and adopted in December 2018. The implications of applying the DMP in practice during the drought have been also evaluated. This study draws important lessons learned that could be applied in other areas suffering from water scarcity and droughts.
\end{abstract}

Keywords: drought management plan; drought; water scarcity; Guadalquivir River; Spain

\section{Introduction}

Global warming and its consequent extreme climate-related events affect, to a greater or lesser extent, the entire planet. The latest IPCC (Intergovernmental Panel on Climate Change) Special Report on Global Warming of $1.5^{\circ} \mathrm{C}$ predicts even worse future climate-change wide-ranging impacts up and until 2100 [1].

Droughts are natural phenomena that affect worldwide although unevenly. The characteristics of droughts (duration, magnitude, and frequency) are specific to each climate region and will determine the degree of stress caused to water resources (in terms of reduction in the soil moisture, low river flows and groundwater levels, drop-in reservoirs storage water levels, etc.), and ultimately, the degree of affection to the rest of spheres of society.

However, the impact of a drought event on the economy, environment, and society will depend on-apart from the inherent characteristics of the drought event-diverse site-specific circumstances, including (i) the resilience and efficiency of the existing water infrastructures, (ii) the existing drought 
management protocols in place, (iii) existing socio-economic factors (such as if there is a fast-growing population, the water use patterns, urbanization, economic development, agricultural irrigation practices, etc.), and (iv) environmental water constraints (e-flows). In contrast, water scarcity episodes occur when water consumption is greater than the renewable available water resources, resulting in overexploited water resources [2].

The magnitude of this issue across Europe is not to be overlooked. Water scarcity and droughts affect around one third of the European territory and over 100 million people [3]. Climate change is projected to increase the intensity, the duration, and the frequency of severe droughts in most of Europe, especially in Mediterranean countries (arid and water-stressed basins) [4,5]. A comprehensive critical review of the historical drought management planning policy evolution in Europe and Spain is presented in Hervás-Gámez and Delgado-Ramos [6].

The occurrence of droughts cannot be avoided as they are a regular feature of any climate. Thus, efforts should be focused on improving the preparedness, risk-reduction based strategies and progressive adaptation in order to avoid (where possible), minimise and manage the potential negative consequences of drought events. It is therefore necessary to apply rational methodologies, which can help water decision makers to find the right and proportionate balance among technically feasible, environmentally sensible, economically efficient and socially acceptable measures to deal with droughts.

However, the major challenge when dealing with a new drought event resides in predicting its duration (which can vary from months to years), the severity (or degree of affection to water resources), and the potential impacts. Hence, there is an importance of integrating reliable forecasting and modeling tools in the development of modern drought management plans (DMPs), so the potential risk can be assessed under a range of possible drought scenarios. This will ensure that the proposed measures and actions of the DMP are sufficiently robust and proportionate to the real drought and water scarcity situation.

In this context, DMPs are key strategic decision-making tools to build resilience to drought extremes for use by water authorities. DMPs should define relevant drought and water scarcity indicators and their thresholds, provide reliable early warning systems, and establish priorities among water users together with a clear action roadmap to be followed during each drought phase. In order to be effective tools and provide consistent support to water decision-makers, DMPs should be based on technical evidence, the latest engineering and science knowledge combined with learning experiences from historical droughts [6]. Despite their importance, the Water Framework Directive (WFD, Directive 2000/60/EC, [7]) does not explicitly require the elaboration of DMPs by member estates. This has been however highly recommended by EU water policies [8-13] and a wide range of European non-legally binding technical guidance documents $[14,15]$. The DMPs can be prepared as supplementary documents to the river basin management plans (RBMPs) along with Art. 13.5 of WFD. So, the DMPs should be developed and implemented according to the WFD requirements.

In Spain, as in many other EU countries, droughts have traditionally been managed as a crisis-driven response only, by applying emergency procedures and urgent measures. However, the lessons learned from past droughts have demonstrated that these are usually hasty, costly, and inefficient solutions in the long-run. It was precisely after the devastating environmental, social, and economic consequences of the 1991-1995 drought period that a paradigm shift towards a drought risk-reduction management approach in Spain was deemed necessary.

The first DMPs for all inter-community river basins in Spain (i.e., rivers that flow across more than one autonomous community) were developed by the river basin authorities (RBA) and approved by the directorate-general for water (DGA) of the Spanish Ministry for the Ecological Transition (MITECO) in 2007 (Orden MAM/698/2007 de 21 de marzo).

Even though the DMPs were not approved until 2007, the 2004-2007 drought was already managed in accordance with those principles. This certainly contributed to avoiding public supply restrictions, 
reducing and mitigating drought impacts, and stressed the importance of public participation in the decision-making process for drought events.

Since the first DMPs were approved in 2007, two planning cycles (2009-2015 and 2015-2021) have been completed in compliance with the WFD. The experience gained during more than a decade of implementing the DMPs across Spain has shown the importance of applying common criteria (including a global system of hydrological indicators) to avoid heterogeneities in the diagnosis and the nature of the actions and measures to be applied in the diverse scenarios and different basins [16].

Based on this, the Royal Decree 1/2016 instructed the revision of all DMPs for all the inter-community river basin districts in agreement with the technical instructions provided by the MITECO before the 31 December 2017. The MITECO prepared the "Technical Instruction for the Elaboration of the Special Drought Plans and the definition of the global system of indicators of prolonged drought and scarcity" in order to ensure that a common methodology was applied among all the RBAs in Spain when diagnosing drought and scarcity situations and implementing the same type and nature of actions and measures.

The RBAs are responsible for their elaboration, management, monitoring, control, and follow-up at the river basin scale (i.e., strategic DMPs). The approving body is the DGA of the MITECO.

The Guadalquivir is the main river in southern Spain (Figure 1) that periodically suffers the consequences of drought events and water scarcity episodes. There is also fierce competition among water users for this scarce water resource in this basin. Therefore, this river basin presents an ideal context to assess how drought risk is ultimately managed according to the recently adopted 2018 Guadalquivir River Basin (GRB) DMP.

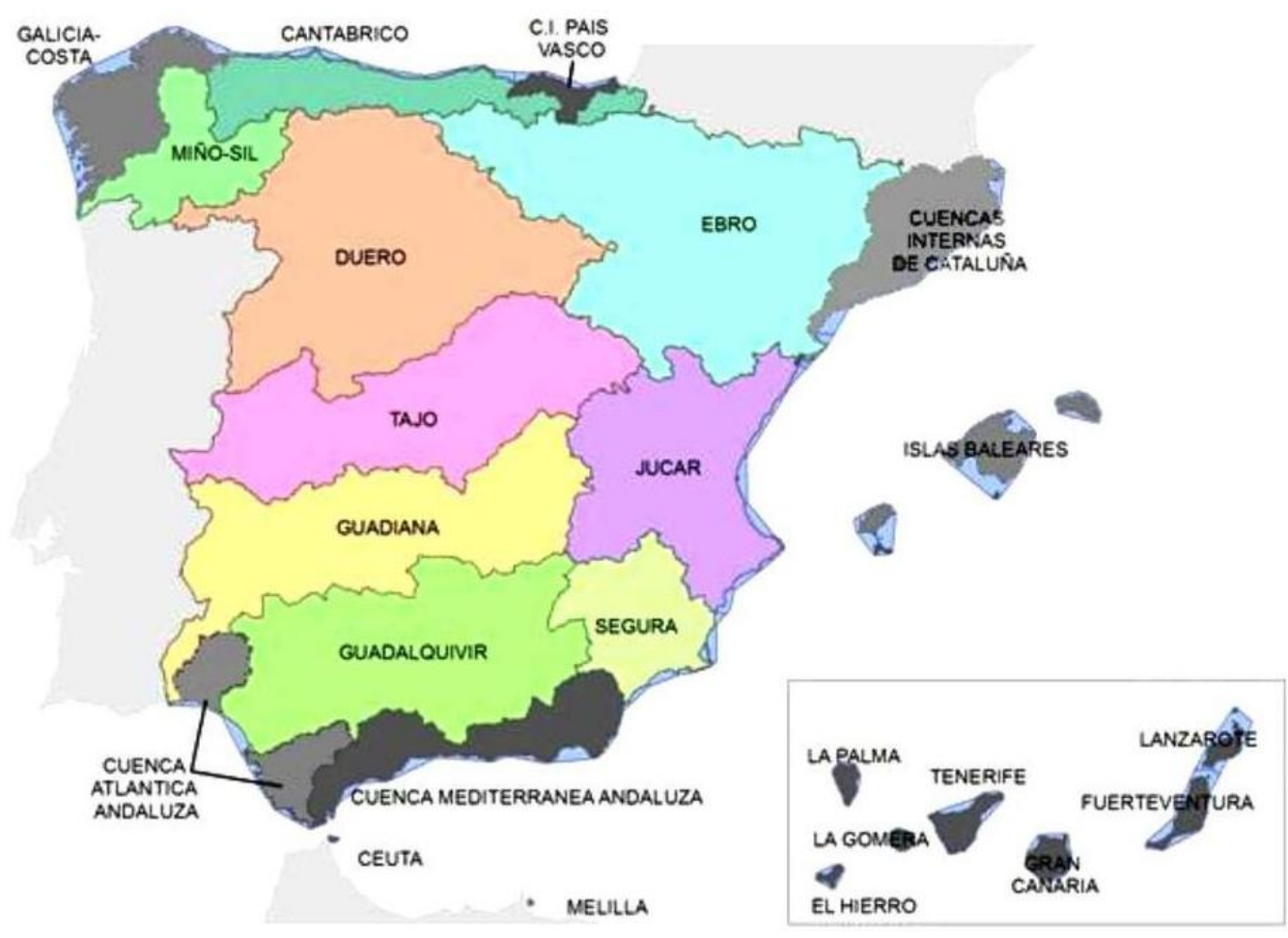

Figure 1. River basins in Spain (source: [17]).

This paper provides a critical assessment of the core technical concepts and principles to be taken into consideration when developing the methodological and operational framework of a DMP. In particular, this paper provides a critical technical assessment of the recently published 2018 GRB DMP. It is evaluated whether and how the proposed drought risk management approach (indicators, thresholds, and measures) would efficiently contribute towards a proactive risk-based management strategy. 
Section 2 provides a critical review of the key aspects of the 2018 GRB DMP in terms of: (i) the methodological (technical) approach in terms of hydrological data sources, reference series, zoning, characterization, diagnosis, and risk evaluation, and (ii) the operational framework in terms of the measures responding to drought and water scarcity. The adopted 2018 GRB DMP (subject to this assessment) is publicly available at the GRB authority webpage [18].

Section 3 presents a technical analysis of the practical implications of applying the 2018 GRB DMP to a specific river sub-basin (Upper Genil River) of the Guadalquivir River Basin and and a set of proposals for improvement are provided.

Section 4 outlines the conclusions and recommendations to enhance future preparedness to drought.

\section{Critical Review of the Key Aspects of the 2018 Guadalquivir River Basin Drought Management Plan}

\subsection{Study Area Description}

The Guadalquivir is the main river in southern Spain (Figure 1) that provides water to a total population of over four million people and over eight hundred thousand hectares for irrigation purposes. This system is currently formed by an interconnected system of 64 large functioning dams [19]. Although there are alternative water resources from aquifers, springs, and water re-use schemes, nowadays, reservoirs are the essential infrastructure to efficiently deal with spatial and temporal climate irregularities distinctive of this catchment area [20].

The Guadalquivir River has a total contributing catchment area of $57,527 \mathrm{~km}^{2}$ and is delimited by Sierra Morena to the north, the Betic mountain to the south, and the Atlantic Ocean. The altitude at the mountainous borders varies between $1000 \mathrm{~m}$ above mean sea level (AMSL) and $3480 \mathrm{~m}$ AMSL, which contrasts with the lower altitudes of the Guadalquivir River valley. The climate is the Mediterranean, which is defined by the warm temperatures $\left(16.8^{\circ} \mathrm{C}\right.$ annual average) and the irregularity of precipitations ( $550 \mathrm{~mm}$ annual average rainfall, oscillating between 293 and $1321 \mathrm{~mm}$ ).

The GRB periodically suffers the consequences of drought events and water scarcity episodes. One of the most recent and notorious drought and water scarcity episode was produced during the 1991-1995 drought period. For the Iberian Peninsula, this event was identified with an approximate 200-year return period and a 5-year duration [21]. The DDF (deficit, duration, frequency) curves developed by the CEDEX are based on 82-year long time series (1930/31-2010/11).

This event resulted in important water scarcity problems and significant economic, social, and environmental consequences (important harvest losses, severe water restrictions to all users, disruptions to services, drinking water deterioration, very low river flows, contamination issues, etc.) [6].

Additionally, the long-term impacts (up to 2100) of climate change predict an increasing frequency in drought events as the 21st-century advances and, consequently, an increase in water scarcity problems due to the forecasted depletion in water resources [22].

The GRB authority is responsible for preparing the DMPs in accordance with the Spanish law 10/2001 hydrological national plan and European water framework directive (Directive 2000/60/CE-Art. 4.6). The final version of the GRB DMP was adopted in December 2018 (Orden TEC/1399/2018, de 28 de noviembre). This framework establishes the general management principles and course of action for different drought and water scarcity scenarios and in each sub-basin.

It is important to highlight that updating a DMP for such an extensive, varied, and intricate river basin is undoubtedly a considerably complex task. The substantial efforts and technical work undertaken by the RBA during the elaboration of the 2018 GRB DMP should, therefore, be acknowledged.

The case of study is the GRB; however, the implications of applying in practice the 2018 GRB DMP have been assessed for the particular case of the Upper Genil River.

The Canales and Quéntar reservoirs form the key water infrastructures that serve water for urban and irrigation purposes. Urban water consumers are up to 300,000 inhabitants, and traditional 
irrigations cover over 4000 hectares. This system is supplemented by a network of GW (groundwater) wells [20]. The system uses an increasing hierarchy of surface water (SW) resources and then, groundwater $(\mathrm{GW})$ resources to meet the demand.

The total annual urban water demand is $37.52 \mathrm{hm}^{3}$, and the total annual irrigation water demand is $25.90 \mathrm{hm}^{3}$ (established in the Guadalquivir RBMP 2015-2021). During years of average precipitation, water demands can be met with SW resources from the reservoirs. However, in years of below-normal precipitation, typically higher GW volume extractions and/or reductions in per right allocation are required. Strategic water decisions are made by the GRB authority on the controlled released outflows from the Quéntar-Canales system. These are critical before the intensive irrigation campaign starts (usually in April) when the water authorities must make responsible management decisions about the best allocation of the available water volume between different water consumers and environmental needs for the rest of the current hydrological year [20].

\subsection{Overview of the 2018 GRB DMP}

The key elements of a DMP in accordance with the MITECO technical instructions and the European technical document "Drought Management Plan Report Including Agricultural, Drought Indicators and Climate Change Aspects Water Scarcity and Droughts Expert Network" [15] are:

(a) a diagnosis system, including the definition of territorial units and environmental characterization;

(b) the definition of a common global indicator and thresholds system (establishing onset, ending, and severity levels of the exceptional circumstances);

(c) actions and measures to be taken in each phase; and

(d) organizational framework: monitoring and follow-up system to deal with drought and subsequent revision and updating of the existing DMP.

Albeit a lengthy document, the 2018 GRB DMP is a well-structured report that contains the aforementioned elements (assessed further in the following Sections).

\subsection{Diagnosis System: Definition of Territorial Units and Environmental Characterization}

One of the key objectives of the 2018 DMPs was to clearly differentiate droughts events (defined as "a natural phenomenon produced by the reduction of rainfall and natural run-off, which occurs independently of anthropic action") from water scarcity episodes (defined as: "the temporary problem of a determined area to meet the water demands for the different socio-economic uses, and therefore it is dependent on human intervention in relation to its use of resource").

Consequently, this conceptual differentiation led to defining different territorial management units (TMU) in terms of water resources to adequately characterize the drought and water scarcity phenomena.

On the one hand, the "prolonged drought TMUs" are related to homogeneous hydrogeological areas in terms of water resources generation (including all watersheds and GW recharge areas according to the RBMP). Therefore, the indicators to be used will be related, principally, with precipitation or streamflow in the natural regime.

The "water scarcity TMUs" are, on the other hand, related to the water demands (or consumption points) and associated ecological systems (according to the water exploitation systems established according to the RBMP). Therefore, the indicators to be used will be related, principally, with meeting the water demands. Generally, the reservoir storage volume is used (for example, this applies to the Upper Genil River, as shown in Section 4).

The GRB includes 25 "prolonged drought TMUs", and each of these is formed by one or more "water scarcity TMUs".

This system is considerably efficient in terms of clearly differentiating droughts from water scarcity episodes. This is important because their underlying causes and consequences are different. This system allows these events to be monitored, diagnosed, and managed differently, with a different set of actions and measures for each specific territorial management unit. 


\subsection{Definition of a Common Global Hydrological Indicator}

A global system of hydrological indicators was established in the 2018 GRB DMP so that drought and water scarcity situations could be identified early enough and foreseen. The methodology followed was:

1. Firstly, the most representative hydrological variable was selected. For example, the precipitation was selected for characterizing the drought events in all "prolonged drought TMU". One variable (or a combination of them, precipitation, reservoir inflow, reservoir storage, GW level, etc.) was selected for characterizing the water scarcity phenomenon in each "water scarcity TMU";

2. Secondly, the relevant hydrological time series were prepared;

3. Thirdly, the indicators were calculated using the sub-basin specific data;

4. Finally, the numerical values obtained were then scaled (between 0 and 1), weighted, and validated using the observed historical series.

This common indicator system allows a homogeneous treatment not only of the entire GRB but among different basins in Spain. The great advantage of this system is that despite the diverse climatic, geographical, or water demand specific conditions, diagnosis results are comparable across different sub-basins. This means that if a similar indicator value is found in two different sub-basins, the drought or water scarcity situation is expected to be similar. Therefore, actions and measures are expected to be of the same type and nature. Tables 1 and 3 show the common progressive measures to be applied across the GRB according to the drought and water scarcity status, respectively.

This highlights significant strides made by all RBAs in Spain towards the harmonization of technical procedures across all the river basins. This system will not only provide support to the RBA decision-making processes to justify actions and measures (especially when declaring formal drought situations) but also when disseminating information to stakeholders, interested parties, and the general public. This example demonstrates how a common indicator system could be implemented at the EU level.

It is important to highlight that despite the undoubted advantages of having a global indicator system, the DMP should be sufficiently flexible to allow actions and measures to be tailored to respond (as required) to specific sub-basin needs. This is paramount in those sub-basins characterized by complex water conflict resolution. For example, in those mixed water systems where there is fierce competition among historical water users (agriculture and households) who share scarce water resources.

Therefore, the DMP should also set out a clear strategy in terms of water use priorities and measures (supply or demand side) in each drought phase and each TMU in order to avoid possible misinterpretation of the DMP that could lead to a potential increase in existing and future conflicts.

\subsection{Streamflow Forecasting Models}

Despite the improvements in the accuracy and reliability of advanced hydrological information and streamflow forecasts, these still remain underused by many water authorities and water decision-makers. Their decisions on how to best allocate the available water resources between the different water users and environmental needs are crucial, especially in water-stressed regions, where there is strong competition for scarce water resources.

In this context, risk-based streamflow forecasts can provide consistent support to water authorities to adopt efficient water resources management strategies and actions, as well as the opportunity to assess in advance the potential environmental and socio-economic consequences. For this study, efficient strategies and actions are those that contribute towards optimizing the use of available water resources to meet the water demands of the system while minimizing environmental impacts (reduction of carbon footprint, the satisfaction of ecological flows, etc.) and reducing costs.

In Spain, for example, the GRB authority is responsible for taking the strategic decisions on controlled released outflows from reservoirs in the GRB. However, they still do not rely on streamflow 
forecasting models to support their strategic decisions but their historical experience in dealing with droughts and managing water resources in this area. The critical decisions on controlled released outflows from reservoirs and water allocation to downstream users are usually taken in the middle of the hydrological year (just before intensive irrigation campaigns commence, usually in April) [20].

The absence of using streamflow forecast models (at least, during the current hydrological year in the course) is not justified. Drought risk-based management decisions should be informed by science and engineering knowledge that is relevant, credible, and delivered in a timely manner. In Spain, the Spanish meteorological agency (Agencia Estatal de Metereología) provides seasonal climate forecasts. Additionally, streamflow forecast models have already been developed and proven to be sufficiently robust and accurate for headwater catchments, such as the Upper Genil River [20].

The use of reliable forecasting models (at least for the current hydrological year) is essential to anticipate, plan, and evaluate potential impacts of a drought, as well as to take adequate and proportionate actions. This is critically analyzed in Section 3.

The methodology used in the 2018 GRB DMP for the calculation of the water scarcity thresholds (that ultimately defines the activation of measures) is based on the assumption that for the next three years, the reference drought event will occur. That is, the 100-year return period drought event for urban water supply systems, the 20-year return period drought event for irrigation water systems, and an intermediate return period drought event for mixed systems (usually, the 20-year return period for all cases except when the urban water supply represents more than $50 \%$ of the total water demand in which case the 100-year return period is used).

The approach followed in the 2018 GRB DMP is considered very conservative, especially when strategic decisions are taken in the middle of the current hydrological year. At that critical decision point (March-April), there is a considerable amount of hydrological information available, which should not be ignored.

For example, if the first 6 months of the hydrological year (from October to March) have been humid and wet, it is unlikely that the 100-year return period drought event will suddenly happen for the next 6 months of the same hydrological year. This is even less likely in catchments with snow storage and melting processes.

This "worst-case" approach has led to undertaking many actions and measures, which later, with the benefit of hindsight, observed to be completely unnecessary or disproportionate. For example, the mobilization of strategic water resources or non-conventional water resources, some restrictions to water demands, etc. with associated negative economic, environmental, and societal consequences, which rarely the water authority would directly assume. This is critically analyzed in Section 3.

\subsection{Reference Period Used}

The diagnosis system established in the 2018 GRB DMP is based on the short hydrological monthly time series (from October 1980 to September 2012, i.e., 32 years).

However, at least a monthly precipitation sample size of 30 years, with 50-60 years (or more) being optimal and preferred to calculate rainfall statistics, is recommended [23,24]. The current WMO (world meteorological organization) climatological standard normal is calculated every 10 years for 30-year periods at the start of every decade from the year ending with digit 1 (1981-2010, 1991-2020, etc.). The WMO has recently recognized [25] that "the optimal period for precipitation is often substantially greater than 30 years" and that "the most recent 5- to 10-year period of record has as much predictive value as a 30-year record". In this respect, it is also important to highlight that the most recent 6-year period of historical hydrological data records is not included in the latest 2018 DMP.

The European water scarcity and drought expert group strongly recommended using the period January 1971 to December 2010 as the reference period for the calculation of the SPI (standardized precipitation index). Only in the case that a lack of data would significantly restrict the number of rainfall stations to be used, a shorter reference period may be used (e.g., 1981-2010). 
An extremely humid or dry period within that short reference period (32 years) might have an impact on the short-term average and standard deviation hydrological values and associated statistical indicators. The degree of affection will depend on the duration and magnitude of the extreme event. This would, therefore, distort a proper comparison with current hydrological values and not allow a sound statistical comparison of wetter and drier climates.

The direct consequences of using the short reference period (instead of the long reference period) are presented in Section 3.

\subsection{Climate Change Assessment}

The 2018 GRB DMP lacks a sound climate change assessment and long-term planning framework (say up to 25-50 years in future) strategy to deal with the key global challenges affecting drought management (impacts of climate change, environmental pressures, and water demand growth).

It is acknowledged that the aim is to periodically update the DMP every 6 years, two years after the end of every RBMP cycle (in the middle of every RBMP cycle).

As the 2018 GRB DMP has been prepared at Strategic Level and based on the anticipated climate change projections for this region, a robust climate change impact assessment is required to evaluate, for example, the resilience of the existing water supply system to face drought events worse than the historical ones and prepare an adaptation programme of measures accordingly. In the long-term, this can help to move from the traditional "reactive" approach to a "proactive" approach and adapt more easily to the climate change effects.

It is, therefore, recommended to include a long-term vision in terms of drought risk management, including planning, adaptation to climate change, and building resilience to droughts. A combination of different water availability and water demand growth scenarios could be assessed, taking into account the data uncertainty. This will help to quantify the supply-demand balance and potential drought and water scarcity risk.

\subsection{Drought Management Measures: Prolonged Drought}

The 2018 GRB DMP defines "prolonged drought" as "the drought produced by exceptional circumstances or that could not reasonably have been foreseen. The identification of these circumstances is done through the use of indicators related to the lack of precipitation during a period of time and taking into account aspects such as intensity and duration (according to definition no. 63 of the Ministerial Order for Hydrological Planning (ORDEN ARM/2656/2008 sobre Instrucción de Planificación Hidrológica (IPH))".

The 2018 GRB DMP also establishes a system to objectively identify the indicator and thresholds of the exceptional circumstances in relation to a prolonged drought situation. The prolonged drought situation is formally declared when the drought indicator value (based on precipitation) is equal or lower to 0.3 . This value has been assigned to that situation in which the natural streamflow regime cannot meet the minimum e-flows (ecological flow regime).

The WFD states in article 4.6: "temporary deterioration in the status of water bodies shall not be in breach of the requirements of the Directive when resulting from natural or force majeure cause, or in case of a reasonably unpredictable event such as "exceptional floods" or "prolonged droughts", or due to reasonably unforeseeable accidents, when all of the established WFD conditions have been met".

It is important to highlight that 4.6 (a) of the WFD states that "all practicable steps are taken to prevent further deterioration in status and in order not to compromise the achievement of the objectives of this Directive in other bodies of water not affected by those circumstances". 
The proposed measures in the 2018 GRB DMP to deal with prolonged drought are to (Table 1):

(i) justify a temporary deterioration of the state of water bodies due to exceptional natural causes;

(ii) apply a less stringent ecological flow regime. However, these proposed measures are not "strictly measures" but the consequences of a prolonged drought situation.

Table 1. Prolonged drought: Types of measures to be applied during the different drought scenarios (own elaboration, data from 2018 GRB (Guadalquivir River Basin) DMP (drought management plans)).

\begin{tabular}{|c|c|c|}
\hline Definition & \multicolumn{2}{|c|}{$\begin{array}{l}\text { Reduction in precipitation that considerably affects the available natural } \\
\text { water resources (surface or groundwater). It does not depend on the } \\
\text { existing water demands. }\end{array}$} \\
\hline Impacts & \multicolumn{2}{|c|}{$\begin{array}{l}\text { It can naturally produce a significant reduction in water quantity and } \\
\text { deterioration of water quality. }\end{array}$} \\
\hline Indicator & \multicolumn{2}{|c|}{ Precipitation and streamflow in natural regime } \\
\hline Global Indicator Value & $0.3-1$ & $0-0.3$ \\
\hline Scenario & Absence of prolonged drought & Prolonged drought \\
\hline Type of Actions & $\begin{array}{l}\text { Control and monitoring. No } \\
\text { temporal deterioration. Comply } \\
\text { with ecological flow regime. }\end{array}$ & $\begin{array}{l}\text { Possibility of justifying a temporal } \\
\text { deterioration and adoption of the } \\
\text { ecological flow regime during a } \\
\text { prolonged drought situation. }\end{array}$ \\
\hline Objective of DMP & \multicolumn{2}{|c|}{$\begin{array}{l}\text { To limit the temporary deterioration of the water status, as well as less } \\
\text { stringent ecological flows (set out in the hydrological plan), to natural } \\
\text { situations of prolonged drought only (not related to scarcity problems). }\end{array}$} \\
\hline
\end{tabular}

It is considered that these measures do not "prevent further deterioration" (as required by the WFD).

The DMP should be a proactive management instrument to implement preventive measures in the first instance (when and where possible), and then mitigate the effects of prolonged droughts. For example, the DMP could include measures to promote water-saving or minimize the water pollution applied to all water-dependent sectors (agriculture, urban development, industry, energy, tourism, transport).

\subsection{Water Scarcity: Indicator and Thresholds}

The water scarcity thresholds are calculated for each specific water scarcity TMU by selecting the most representative variable in terms of resource availability evolution (precipitation, reservoir storage volume, reservoir inflow, GW level, etc.).

In the case of the GRB, the reservoir storage volume has been selected for all TMUs except for one (in which precipitation has been used). In those systems with irrigation demands, two different periods have been analyzed: from October to March and from April to September (when the irrigation campaigns generally occur).

The water scarcity thresholds are defined in the DMP by "the capacity of a specific territorial management unit to face or minimize the impacts of a possible drought event". The model used to define the thresholds is based on a volumetric balance using a monthly time step, taking into account the inputs, available storage volume, and outputs for the next three years. The calculation methodology used to determine the water scarcity thresholds is presented in Equation (1):

$$
\begin{aligned}
\text { Stored Volume } & + \text { Streamflow Contribution }- \text { Evaporation }- \text { Ecological Flows } \\
& \geq \text { Water Demand }+ \text { Strategic Water Reserves }
\end{aligned}
$$

Based on the results from applying Equation (1) to each water system, the following water scarcity thresholds have been defined: 
- Pre-alert: there is available water supply to meet the water demand for the next three years (in compliance with the guarantee criteria established in the RBMP).

- Alert: there is available water supply to meet the water demand for the next two years (in compliance with the guarantee criteria established in the RBMP).

- Emergency: there is available water supply to meet the water demand for the next year (in compliance with the guarantee criteria established in the RBMP).

Given the high inter-annual climate variability within the GRB, reservoirs have traditionally been designed to store three times the water demand of the system. The GRB DMP states that based on existing drought records, a three-year drought prevention period should be used. However, this has been shown to be insufficient since the worst and most recently recorded drought event was the 1990/91-1994/95 (5-year duration, Table 2).

Table 2. Main recent historic droughts with duration 2 years or longer on record in the GRB (own elaboration, data from 2018 GRB DMP).

\begin{tabular}{cccccc}
\hline \multicolumn{2}{c}{$\begin{array}{c}\text { Hydrological Year } \\
\text { (from Oct. to Sept.) }\end{array}$} & Duration & Total Deficit & $\begin{array}{c}\text { Mean Annual } \\
\text { Deficit }\end{array}$ & $\begin{array}{c}\text { Maximum } \\
\text { Annual Deficit }\end{array}$ \\
\hline Start & End & (Years) & $\mathbf{( m m )}$ & $\mathbf{( m m )}$ & $\mathbf{( m m )}$ \\
\hline $1971 / 72$ & $1976 / 77$ & 6 & 276 & 55 & 101 \\
$1979 / 80$ & $1982 / 83$ & 4 & 591 & 148 & 204 \\
$1985 / 86$ & $1986 / 87$ & 2 & 68 & 34 & 41 \\
$1990 / 91$ & $1994 / 95$ & 5 & 744 & 149 & 270 \\
$1998 / 99$ & $1999 / 2000$ & 2 & 334 & 167 & 280 \\
$2004 / 05$ & $2007 / 08$ & 4 & 81 & 27 & 44 \\
\hline
\end{tabular}

In fact, the devastating consequences of this drought event lead to the GRB authority to undertake a wide range of strategic and emergency works across the whole GRB to ensure new water supply sources (new river catchments, water transfers among sub-basins, GW wells), apart from severe water demand restrictions (which had considerable social, environmental and economic consequences).

It can be seen from Table 2 that long-term droughts of 3 years duration (or longer) occur almost every decade, so they are not rare events in this river basin. In the last decade (2010-2019), however, there have been dry spells consisting of a single season or multiple seasons (usually a dry summer followed by dry autumn, for example, during July 2015-January 2016 and May 2017-November 2017). Additionally, the Mediterranean area (especially, the arid, semi-arid, and water-stressed basins) is very sensitive to climate change, and it is predicted that future droughts events might be worse than historical droughts. That is, the return periods might be lower (or higher frequency of occurrence) while the duration and deficit might be higher.

Therefore, the 2018 GRB DMP should demonstrate that the system is resilient, at least, to the most recent worst historic drought on record (i.e., the 1990/91-1994/95 drought event).

This means that if that event was to occur again given the current water demands and available water resources options, the adoption of Emergency Drought Orders or Decrees would not be required.

In fact, strategic DMPs should also consider what would mean in practice the prediction that future drought might be worse than historic droughts. Nonetheless, it should be acknowledged that designing for an improved level of resilience to droughts conditions, considerably worse than those already experienced, might lead to unaffordable or disproportionate costs together with the exposure to an unknown area due to the lack of experience dealing with this severity level. These situations could be dealt with with the use of emergency drought orders or decrees.

This highlights again the need for a long-term planning approach as part of a strategic DMP, including the modeling of a range of drought scenarios and providing a sound climate change assessment. 


\subsection{Water Scarcity Management: Measures}

The standard progressive measures to be applied across the GRB according to the water scarcity status are shown in Table 3.

Table 3. Operational water scarcity: Types of measures to be applied during the different water scarcity scenarios (own elaboration, data from 2018 GRB DMP).

\begin{tabular}{|c|c|c|c|c|}
\hline Description & \multicolumn{4}{|c|}{$\begin{array}{l}\text { Reduction in available water resources that could risk meeting the existing } \\
\text { socio-economic water demands of the specific water system. }\end{array}$} \\
\hline Impact & \multicolumn{4}{|c|}{$\begin{array}{l}\text { Socio-economic impacts due to the limitation in available water resources for water use } \\
\text { (which could be otherwise addressed in a normal situation). }\end{array}$} \\
\hline Indicator & \multicolumn{4}{|c|}{$\begin{array}{l}\text { Storage reservoir volume, reservoir inflow, streamflows, snow storage, groundwater } \\
\text { level, etc. }\end{array}$} \\
\hline Global Indicator & $1-0.5$ & $0.3-0.5$ & $0.15-0.3$ & $0-0.15$ \\
\hline Value & Absence & Moderate & Severe & Extreme \\
\hline Scenario & Normal & Pre-alert & Alert & Emergency \\
\hline $\begin{array}{l}\text { Type of Actions } \\
\text { and Measures to } \\
\text { Be Activated }\end{array}$ & $\begin{array}{l}\text { General planning } \\
\text { and monitoring }\end{array}$ & $\begin{array}{l}\text { Public awareness, } \\
\text { water-saving, and } \\
\text { monitoring }\end{array}$ & $\begin{array}{l}\text { Management } \\
\text { (demand/supply), } \\
\text { control, and } \\
\text { monitoring }\end{array}$ & $\begin{array}{l}\text { Intensify actions } \\
\text { already considered } \\
\text { in the alert scenario. } \\
\text { Possible adoption } \\
\text { of extraordinary } \\
\text { measures }\end{array}$ \\
\hline Objective & \multicolumn{4}{|c|}{$\begin{array}{l}\text { Progressive establishment of measures in order to delay or avoid the entrance in the } \\
\text { most severe phases of scarcity, mitigating their negative consequences on } \\
\text { socio-economic uses. }\end{array}$} \\
\hline
\end{tabular}

Despite the potential economic, environmental, and social wide-ranging impacts, the actions and measures to deal with droughts and water scarcity have been selected without providing a sound multi-criteria study to justify the proposals are technically feasible, economically efficient, socially acceptable, and environmentally sustainable.

Tsakiris [26] highlighted that "The selection of measures should always start with the scenario of business as usual, followed by the easiest and low-cost actions, and then gradually moving to more expensive and difficult to implement actions. Priority should be given to reallocation of water resources and water saving activities. Priority also should be given to the temporary measures which will not remain when the situation comes back to normal. We should have in mind that drought is a temporary phenomenon and can be dealt with temporary measures. Costly permanent structural measures are not generally in the centre of the scope of drought management plans. However, they can be selected only if it is deliberately proved that the suffering systems have quite inadequate capacity to face even usual drought years".

This was also highlighted by [27] in relation to the 2007 DMP: "One of the deficiencies of the DMPs from 2007, still in force, is that they do not appropriately contemplate drought impacts on different economic sectors. For this reason, the afore-mentioned technical instruction will include criteria to evaluate these impacts in the different river basin districts. This means that the plans to be approved in 2017 will probably contain a homogeneous and adequate estimation of the economic impacts of droughts in the whole Spanish territory". This is still one of the key deficiencies of the 2018 GRB DMP.

Another difficulty is that the hierarchy and priority assigned to each type of measure within each water scarcity scenario is not provided, with regards to which should be the core of the DMPs' scope. There are a set of measures that could be applied in each water scarcity zone, but the order of application is not given. There is also ambiguity on the priority of use among water users and environmental needs. This undermines the definition of the adequate measures to be undertaken and the achievement of environmental objectives in line with the WFD. 
Although it is acknowledged that specific actions would be dependent on site-specific circumstances (nature of the supply and demand system, time of year, precedent conditions, climatic predictions, etc.), the Strategic DMP does not provide a clear sequence of drought trigger intervention responses to be followed during each water scarcity phases, with generalist measures to be applied.

In Spain, water companies elaborate operational and contingency DMPs for urban water supply systems serving more than 20,000 people in order to ensure water supplies under drought situations.

Therefore, the Operational DMPs will detail the specific measures to be applied in the particular water system, in accordance with the directions provided in the Strategic DMP. However, at the moment, the Operational and Strategic DMPs are not prepared in parallel. This fact sometimes lead to the mismatch between the overarching principles set out in the Strategic DMPs and the specific assessments of the Operational DMPs. In order to ensure that both are completely aligned, it is fundamental that these are prepared together and with the required levels of interaction/liaison with third parties.

It is also considered necessary to relate each measure not only with the water scarcity indicator but also with the drought indicator (SPI).

A crucial aspect of any program of measures is that: "their action methods and established measures must be applied once the interested parties have agreed upon them: administrations, civil society, scientific community, NGOs etc." [27].

\section{Practical Implications and Limitations When Applying the 2018 GRB DMP. Proposed Improvements}

\subsection{Overview}

After reviewing the key elements of the 2018 GRB DMP and identifying the main strengths and weaknesses, a technical analysis of the practical implications of applying the 2018 GRB DMP to a specific sub-basin area (the Upper Genil River) has been undertaken, and a set of proposals for improvement has been provided.

The following aspects have been assessed:

(a) Implications of using the short reference period (instead of the long reference period) to calculate the drought indicator system (standardized precipitation index) and water scarcity indicator system.

(b) Limitations of using the 2018 GRB DMP water scarcity thresholds and proposed alternative water scarcity thresholds.

(c) Use of streamflow forecast models to improve drought management during the current hydrological year. The forecast model used for this assessment is AQUAFOR (a simple and robust monthly and yearly streamflow forecasting model developed by the University of Granada [20]). The results obtained from using AQUAFOR forecast model (in combination with the aforementioned proposed alternative water scarcity thresholds) were compared with the outcomes from managing a drought event following the 2018 GRB DMP protocol of action. The efficiency in optimising the use of the available water resources to meet the existing water demands of the system was compared. The potential cost implications and environmental impacts were also discussed.

\subsection{Implications of the Selected Reference Period on the Drought Indicator System (Standardized Precipitation Index)}

As mentioned in Section 2.6, the diagnosis system established in the 2018 GRB DMP is based on the short hydrological monthly time series (from October 1980 to September 2012, i.e., 32 years), and this has a series of limitations. 
A comparative assessment has been undertaken to show the differences in the SPI calculation using the short and long reference periods and, based on that, what that would actually mean in terms of diagnosing the drought situation and the response.

The aim of the SPI is to objectively identify the variation in the total precipitation (associated with a specific number of months) compared with the long-term average historical precipitation (for the same period). The reduction in precipitation in comparison with the long-term average historical precipitation is the key driver to identify a drought situation. Therefore, negative SPI values mean drier periods than normal. The magnitude of the event is given by the absolute value of the SPI [28].

Figure 2 shows a comparative analysis of the SPI for six cumulative months (SPI-6m) using both the short and the long reference series for the Canales and Quéntar reservoirs (Upper Genil River sub-basin) within the GRB. Note: The SI unit of volume is the cubic meter $\left(\mathrm{m}^{3}\right)$. In this article, the cubic hectometer unit $\left(\mathrm{hm}^{3}\right)$ has been used. That is, $1 \mathrm{hm}^{3}=10^{6} \mathrm{~m}^{3}$.

The average annual precipitation values for Canales and Quéntar reservoirs are $1109.54 \mathrm{~mm}$ (using the most recent 31-year short reference period, Oct. 1988-Sept. 2019) and $1184.04 \mathrm{~mm}$ (using the long time series, Oct. 1951-Sept. 2019). This means approximately a $6.3 \%$ reduction in precipitation when using the short time series.

Figure 2 shows how the most severe drought events (e.g., 1991-1995, 2004-2007) are characterised with lower SPI absolute values when using the short reference period (i.e., lower return period and greater probability of occurrence). This means that an extreme/severe drought event (1991-1995, 2004-2007) would be identified as "more normal" or moderate event using the short time series than using the long time series.

This is because one of the most severe recently recorded drought events occurred from 1991 to 1995 (Table 2). This 5-year period of intense drought had a total rainfall deficit of $744 \mathrm{~mm}$ (mean annual deficit of approximately $149 \mathrm{~mm}$ ). Logically, an event of these characteristics has a considerable impact on the mean and standard deviation values of precipitation over a short period of time.

This means that extreme (humid or dry) events might not be adequately depicted using the short reference period to efficiently inform the early warning system. Consequently, the statistical indicator (SPI) might not be adequately representative of the event since there is not a sufficiently long record of data. An incorrect diagnosis of the situation could lead to activate drought measures at the wrong time, with the associated environmental, social and economic consequences.

It is, therefore, recommended that the long-term historical precipitation and streamflow series are used for the correct characterization of drought events. The 2018 GRB DMP justifies the use of the most recent short reference period because it reflects better the most recent changes in climate in comparison with the long-term data series. However, the historical data sets provide important information for adequate probabilistic treatment, and it cannot just be disregarded. An alternative option could be to use a weighting system such that the most recent years are assigned a higher weight in comparison with the old years. 


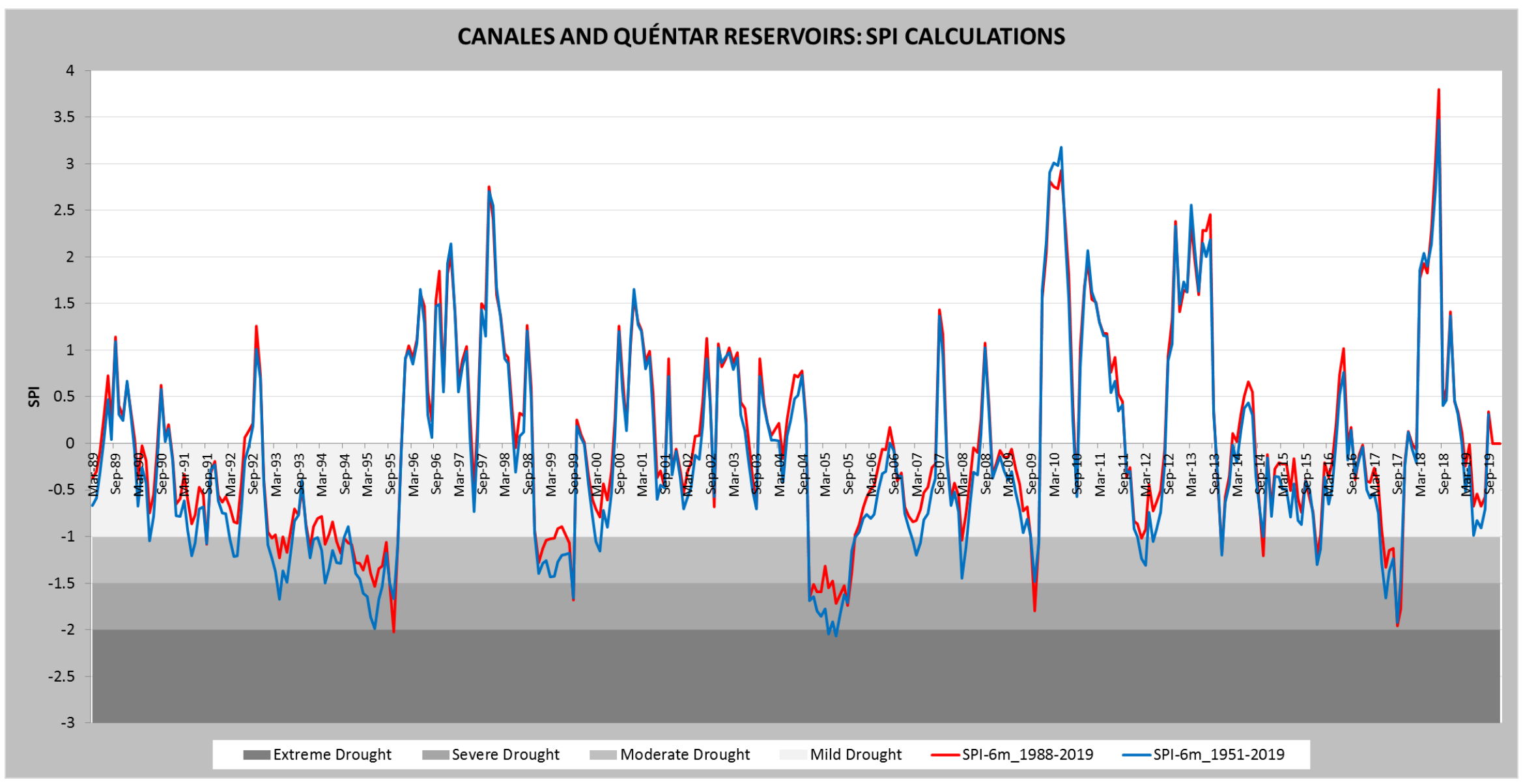

Figure 2. SPI (standardized precipitation index) using the short and long-term time series for the Canales and Quéntar reservoirs (Upper Genil River sub-basin, Guadalquivir River Basin). 


\subsection{Implications of the Selected Reference Period on the Water Scarcity Indicator System}

The aim of the water scarcity indicator system is to objectively identify the potential temporal difficulty in meeting the water demands of a specific water system. The streamflow time series are the input data used to calculate the water scarcity thresholds (refer to Equation (1)).

The difference in the total renewable average annual streamflow for the entire GRB, using the long-time series (Period 1940/41-2011/12) in contrast to the short-time series (Period 1980/81-2011/12) is $1168 \mathrm{hm}^{3} /$ year (according to the data provided in the 2018 GRB DMP).

Therefore, using the lower contribution inputs in the system (i.e., the short-time series) will mean higher water scarcity threshold values. That is, under the same water demand circumstances, the water system will enter earlier and more often into the water scarcity thresholds using the short time series compared with the long-time series. This could lead to activate "more extreme" measures and earlier than actually required, with the associated environmental, social, and economic consequences. This is demonstrated in Sections 3.4 and 3.5.

We, therefore, consider that the length of the historical time-series used (i.e., 32 years) in the 2018 GRB DMP generates uncertainty to (i) adequately depict and characterize the extreme climate-related events, (ii) define adequately the drought and water scarcity indicators, and (iii) provide a reliable early warning system. Extreme event strikes are the result of stochastic processes with usually much larger time horizons than the baseline reference period against which risk is assessed.

It is, therefore, recommended that the long-term historical precipitation and streamflow series are used for the correct characterization of water scarcity episodes.

\subsection{Limitations of Using the 2018 GRB DMP Water Scarcity Thresholds and Proposed Alternative Water Scarcity Thresholds}

For the Upper Genil River sub-basin (known as the "Canales and Quéntar reservoirs water system"), the water scarcity values set out in the 2018 GRB DMP are shown in Table 4.

Table 4. Canales and Quéntar reservoirs stored volume water scarcity thresholds (from 2018 GRB DMP).

\begin{tabular}{ccccccccccccc}
\hline \multirow{2}{*}{ Scenario } & \multicolumn{1}{c}{ 2018 GRB DMP Water Scarcity Thresholds-Stored Volume Canales and Quéntar Reservoirs $\mathbf{( h m}^{3}$ ) } \\
\cline { 2 - 12 } & Oct & Nov & Dc & Jan & Feb & March & April & May & June & July & August & Sept \\
\hline Pre-alert & 65 & 65 & 65 & 65 & 65 & 65 & 51 & 51 & 51 & 51 & 51 & 51 \\
Alert & 43 & 43 & 43 & 43 & 43 & 43 & 37 & 37 & 37 & 37 & 37 & 37 \\
Emergency & 15 & 15 & 15 & 15 & 15 & 15 & 16 & 16 & 16 & 16 & 16 & 16 \\
\hline
\end{tabular}

It can be observed that the values are constant from October to March, and from April to September (which correspond to the irrigation campaign).

Figure 3 shows the 2018 GRB DMP water scarcity thresholds, the historically observed reservoir stored volume records (from October 1999 to September 2019, this period of time corresponds to the available observed data obtained from the "Automatic Hydrological Information System" known as $\mathrm{SAIH},[29])$, as well as the long-term average monthly reservoir stored volume values. 


\section{Canales and Quéntar Reservoirs - Historically Observed Storage Volume and PES-2018 Water Scarcity} Thresholds $\left(\mathrm{hm}^{3}\right)$

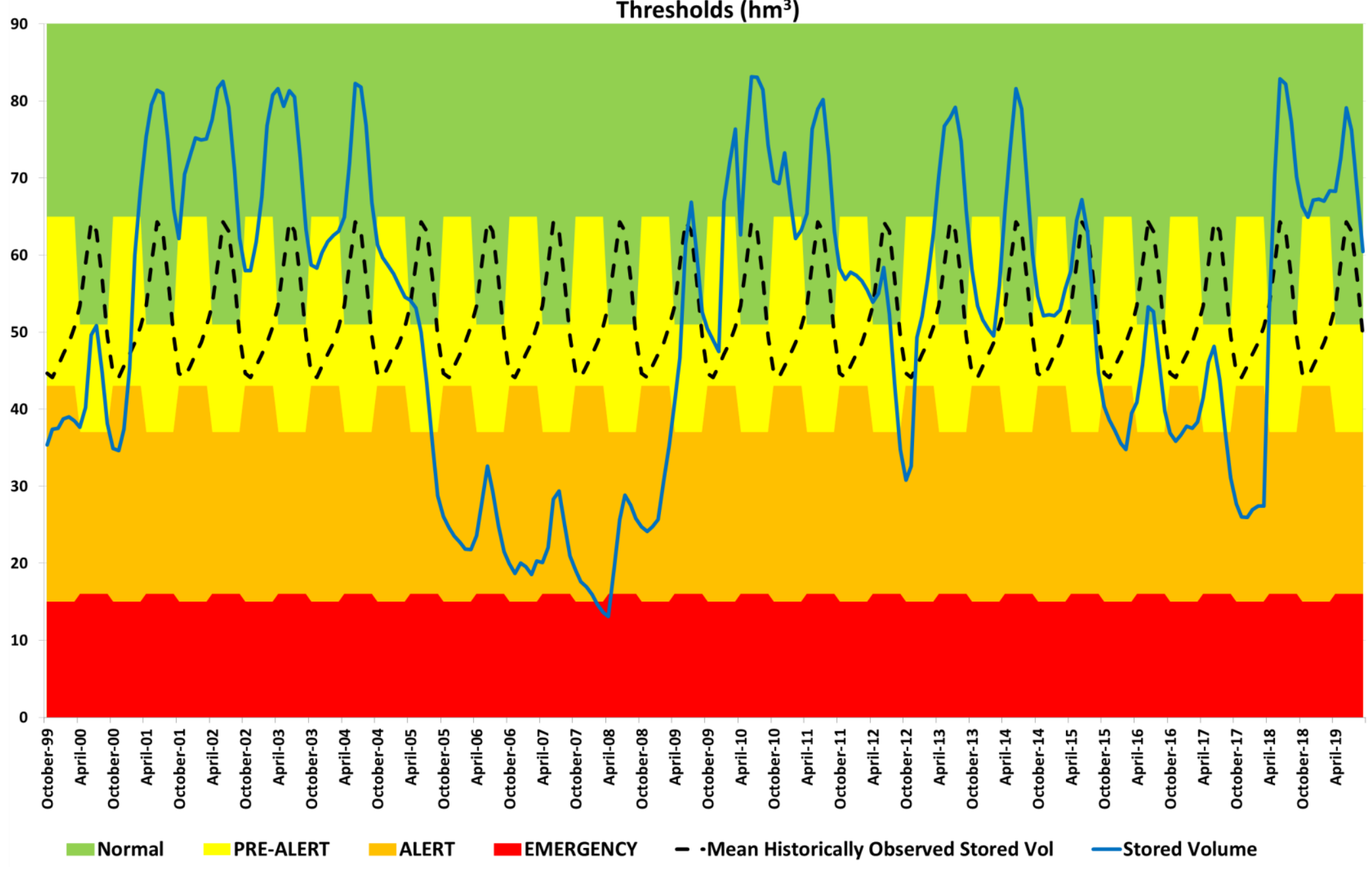

Figure 3. Canales and Quéntar reservoirs: Historically observed stored volume, Mean historically stored volume, and 2018 GRB (Guadalquivir River Basin) DMP (drought management plans) trigger curves (own elaboration). 
The critique of this system is presented below:

(a) It is unclear why the thresholds values are constant (from October to March and from April to September). This is not representative of the normal reservoir storage operating curve. The thresholds should vary monthly, depending on the intrinsic characteristics of the system and the stored volume expected for that time of the year.

For example, at the beginning of the hydrological year (October-November), the stored volume values are expected to be at their lowest values of the year. After the summer months and the irrigation campaign from the previous hydrological year (April to September), the reservoir is sufficiently empty to provide its water storage and flood protection function for the winter months.

(b) Pre-alert monthly value of $65 \mathrm{hm}^{3}$ (from October to March): This value $\left(65 \mathrm{hm}^{3}\right)$ is relatively high $(83.8 \%)$ when compared with the total storage capacity of the system $\left(83.5 \mathrm{hm}^{3}, 70 \mathrm{hm}^{3}\right.$ Canales reservoir and $13.5 \mathrm{hm}^{3}$ Quéntar reservoir). Additionally, this value represents $81 \%$ of the average annual streamflow $\left(80.42 \mathrm{hm}^{3}\right.$ for Canales and Quéntar).

Figure 3 shows how, for the historical average year, the system would enter into the pre-alert scenario from October to March (which is not logical). In fact, looking at the historical data set presented in Figure 3, the system is always in pre-alert at the beginning of the year (except in October 2010, when the stored volume was just slightly higher than $65 \mathrm{hm}^{3}$ ).

One of the measures sets out in the 2018 GRB DMP for the pre-alert scenario is the possibility of mobilizing strategic GW resources. However, if the strategic GW wells are activated and later on these were not actually required, it is important to consider the unnecessary economic and environmental consequences. This is demonstrated in Section 3.5.

(c) Emergency threshold value of $15 \mathrm{hm}^{3}$ (October-March) and $16 \mathrm{hm}^{3}$ (April-September): these values are relatively low in comparison with the annual household and irrigation water demands of this this system $\left(37.52 \mathrm{hm}^{3}\right.$ and $25.90 \mathrm{hm}^{3}$, respectively as described in Section 2). These values are also relatively low in comparison with the historical minimums recorded in this system. This means that if we face a severe drought situation (similar to the 1991-1995 drought), this would be identified as an "Emergency" situation, considerably late.

(d) The alert and emergency thresholds hardly offer any relevant information, as shown for example during the 2004-2007 drought period.

The aforementioned results clearly demonstrate that the 2018 GRB DMP water scarcity thresholds are not representative of a real water scarcity situation of this system. Incorrect scarcity thresholds (pre-alert, alert, and emergency) can lead to the activation of inadequate or disproportionate actions at the wrong time, with considerable economic, energetic, social, and environmental consequences. This is demonstrated in Section 3.5.

Table 5 shows the proposed alternative water scarcity thresholds, and Figure 4 shows these proposed alternative water scarcity thresholds in relation to the mean historical year and observed storage volume values.

Table 5. Canales and Quéntar reservoirs: Proposed stored volume water scarcity thresholds (own elaboration).

\begin{tabular}{ccccccccccccc}
\hline \multirow{2}{*}{ Scenario } & \multicolumn{8}{c}{ Proposed Water Scarcity Thresholds-Stored Volume Canales and Quéntar Reservoirs $\mathbf{( h m}^{3}$ ) } \\
\cline { 2 - 13 } & Oct & Nov & Dc & Jan & Feb & March & April & May & June & July & August & Sept \\
\hline Pre-alert & 42 & 42 & 41 & 42 & 44 & 46 & 50 & 53 & 57 & 55 & 49 & 44 \\
Alert & 32 & 32 & 32 & 33 & 35 & 37 & 41 & 43 & 48 & 46 & 39 & 34 \\
Emergency & 20 & 19 & 21 & 22 & 25 & 26 & 29 & 31 & 36 & 34 & 27 & 22 \\
\hline
\end{tabular}




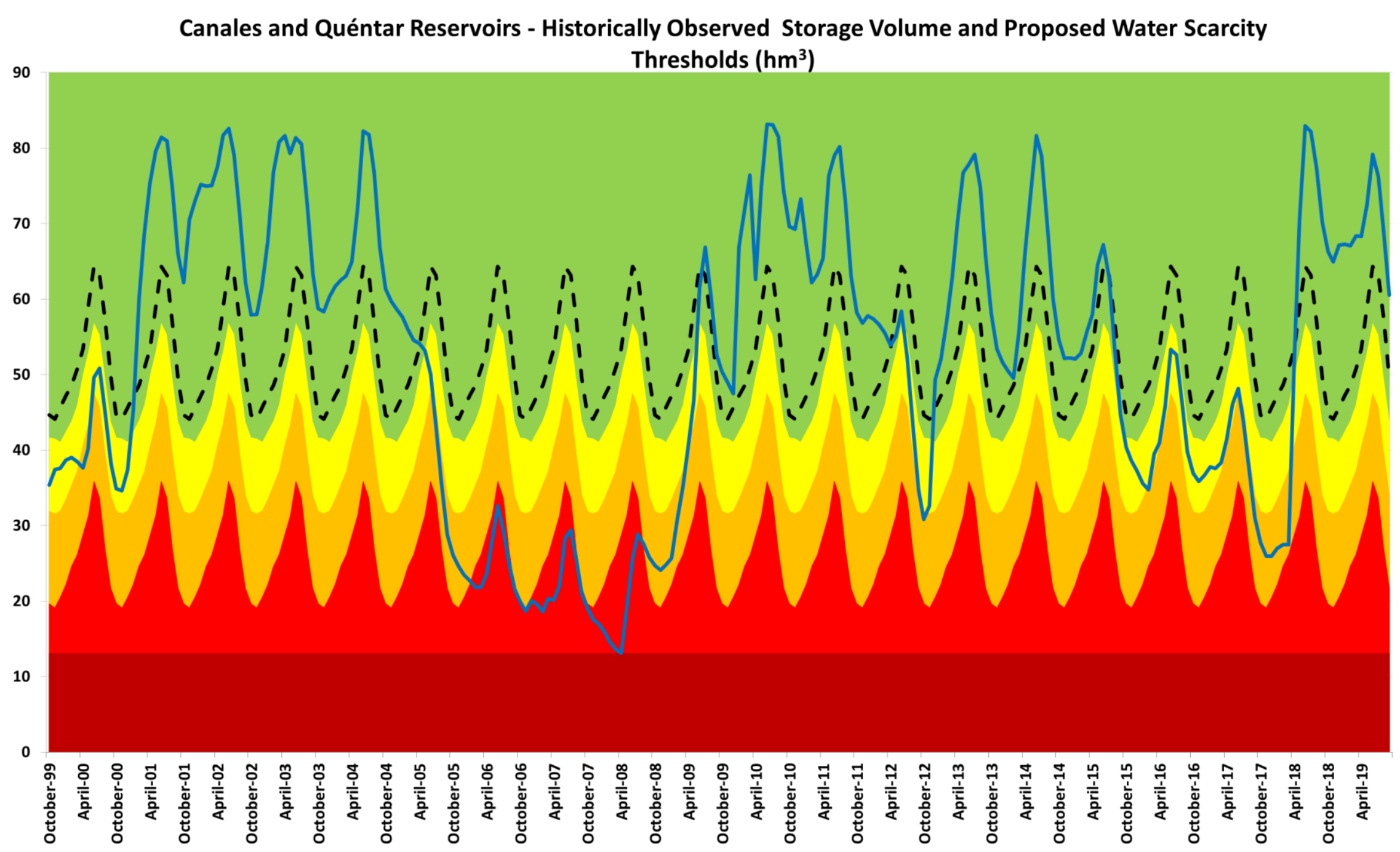

Normal I - PRE-ALERT II - ALERT =III - EMERGENCY VI - MIN OBS. - -Mean Historically Observed Stored Vol —Stored Volume

Figure 4. Canales and Quéntar reservoirs: Historically observed stored volume, Mean historically stored volume, and proposed trigger curves (own elaboration). 
The purpose has been to identify different phases of water scarcity in the system, so proportionate measures can be progressively applied to avoid entering in more severe phases. The proposed pre-alert scenario indicates a certain deviation from the modeled average year, so within this scenario, measures such as raising public awareness, promoting water savings and efficiency, as well as monitoring the key hydrological and environmental variables, should start. Therefore, this is one of the key differences with respect the 2018 GRB DMP, which in the pre-alert scenario establishes the possibility of mobilising strategic GW resources (refer to Appendix B). This is difference is shown and described in Section 3.5.

The proposed alert and emergency scenarios show greater deviations from modeled average year and, therefore, entering in these thresholds indicate the time at which the strategic measures need to be activated (such as mobilizing additional conventional or non-conventional sources, facilitating and optimizing trading assignments in water right markets and applying progressive water restrictions to irrigation and households). It is important to highlight that bottom-up approaches, such as demand management, are also recognized as critical factors to resilience planning alongside more traditional supply-side management representing a paradigm shift [30].

The proposed water scarcity thresholds have been calculated using the software MODSIM-DSS from the University of Colorado, and all the input data are described in Appendix A. The evolution of the reservoir storage volume has been modeled based on the historical streamflow series and using the projected water demands set out in the Guadalquivir RBMP (2015-2021). To define the water scarcity thresholds, only the primary water resources of the system have been included (i.e., regulated SW resources from Canales and Quéntar reservoirs). The use of alternative or complementary strategic water resources has not been included (since the strategic GW wells infrastructure will be activated only when the system enters in the proposed alert and emergency trigger curves). This is shown in Section 3.5.

The modeled average reservoir storage volume year and the standard deviation (STD) have been calculated. The different thresholds have been estimated by evaluating the modeled water scarcity thresholds in relation to the historical reservoir storage data and identifying the values at which it is necessary to activate alternative water resources (and quantity) or/and apply water demands reductions. Hence, the pre-alert, alert, and emergency scenarios have been estimated as the modeled average reservoir storage volume values minus $0.3 \times \mathrm{STD}, 0.7 \times \mathrm{STD}$, and $1.2 \times \mathrm{STD}$, respectively.

Figure 4 shows the proposed water scarcity trigger curves obtained following the abovementioned methodology. It can be appreciated how the proposed system would depict considerably well the onset, severity level, and end of historical water scarcity situations (for example, the drought 2004-2007).

It can be, therefore, concluded that the alternative water scarcity thresholds address the aforementioned shortcomings of the 2018 GRB DMP water scarcity thresholds.

\subsection{Use of Streamflow Forecast Models to Improve Drought Management during the Current Hydrological Year}

Usually, it is easy to look back to evaluate historical drought events (when all the relevant information is available) and then identifies when, how, and what specific actions should have been undertaken by who, so the potential negative drought impacts might have been minimized. Indeed, important lessons can be learned from managing historical drought events, but the reality is that there are not two completely equal drought events.

When we face a new drought episode, the major challenge is precisely identifying and characterizing the type of event we will be dealing with, in terms of its duration (which can vary from months to years), its severity (or degree of affection to available water resources), and the potential economic, social, and environmental effects. If this information was known beforehand, it would be much easier to activate the required preventive, adaptive, and proportionate actions at the right time to deal with the real situation.

While establishing relevant water scarcity thresholds may be an approach to identify a water scarcity situation and the type of measures to be applied, these trigger curves alone are not sufficient to ensure the most appropriate response to a potential water scarcity situation. The water scarcity curves 
need to be looked at in combination with using forecasting tools. This is especially important during the current hydrological year, during which there is a considerable amount of relevant information with the increase in the number of observed months, which should not be dismissed.

A comparative assessment has been carried out to assess how a water scarcity situation had been managed in the following scenarios:

(i) Scenario I (S-I): Following the 2018 GRB DMP protocol of action;

(ii) Scenario II (S-II): Using a streamflow forecast model in combination with the proposed alternative water scarcity thresholds described in Section 3.4.

The forecast model used for this assessment is AQUAFOR (a simple and robust monthly and yearly streamflow forecasting model developed by the University of Granada, [20]). The model outputs three probabilistic forecasts: optimistic or upper streamflow forecast (this corresponds to the 90th percentile), mean streamflow forecast (that correspond to the average forecast), and pessimistic or lower streamflow forecast (this corresponds to the 10th percentile). For this comparative assessment, the mean streamflow forecast has been chosen. However, water authorities can make use of the upper and lower risk-based streamflow forecasts as well to assess different future water scenarios and adopt risk-based management decisions.

For the particular case of application, the Upper Genil River (like many other Mediterranean basins where the agriculture sector plays a key role), the critical decision point is in the middle of the hydrological year (just before intensive irrigation campaigns commence, usually in April). At this time, the GRB authority decides on controlled released outflows from reservoirs and water allocation to downstream water users. To inform these decisions, an assessment of the current hydrological year (in terms of precipitation, reservoir storage volume, and streamflow) in relation to the mean historical year is undertaken by the GRB authority. The type of actions and measures to be applied in order to ensure water supplies to the urban water supply-demand (UWSD) and irrigation water demand (IWD) will depend on the reservoir storage volume and water scarcity scenario (normal, pre-alert, alert, and emergency), as identified in the 2018 GRB DMP (Appendix B).

The 2004-2008 drought period has been selected for this assessment. This has been considered to be sufficiently recent, long, and severe drought event to show the implications of using the 2018 GRB DMP. Figure 5 shows the observed precipitation, streamflow, and reservoir storage during the 2004-2008 drought period for the system of study, compared with the historical mean values.

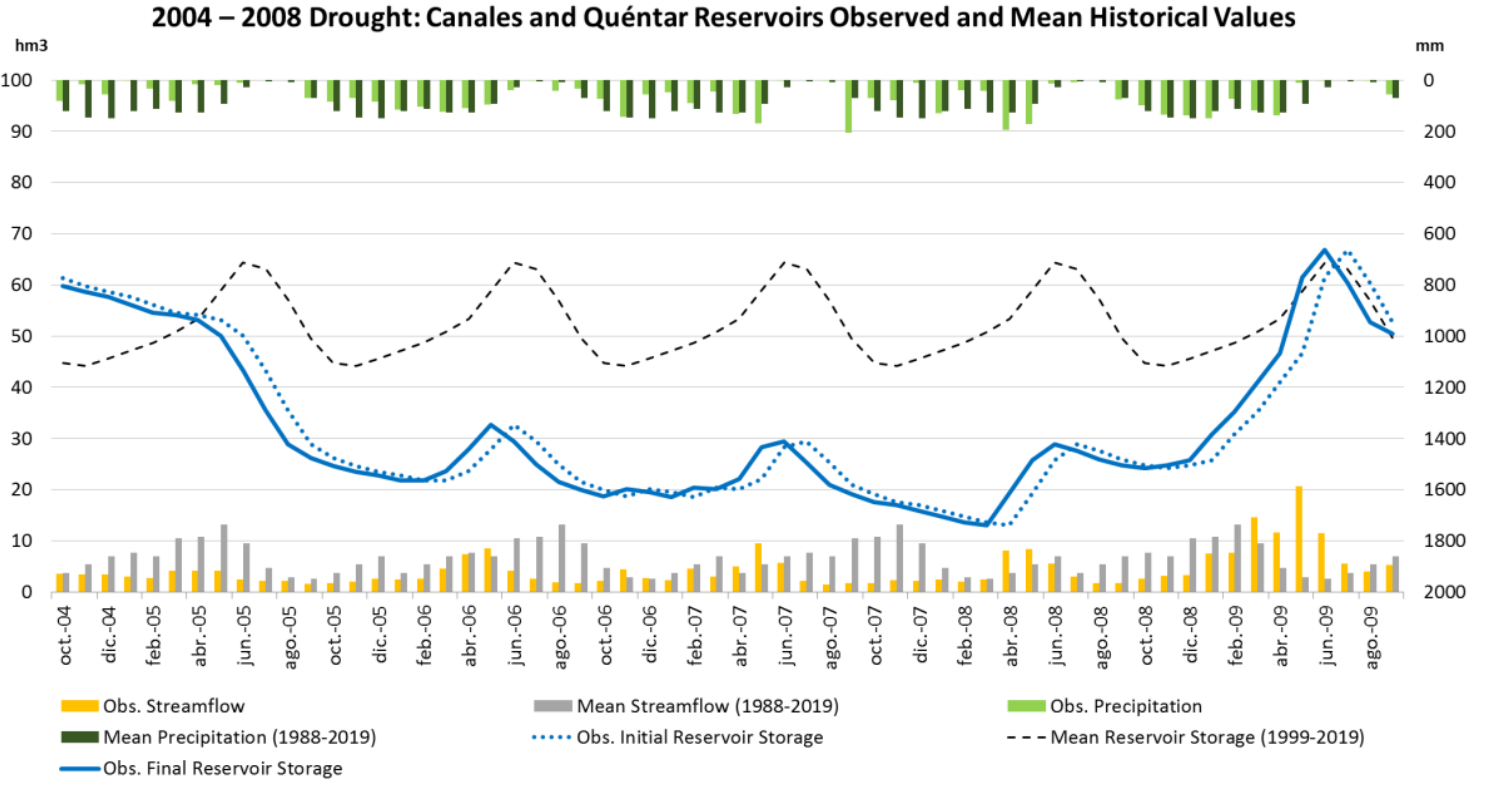

Figure 5. 2004-2008 drought: Canales and Quéntar reservoir observed and average precipitation, streamflow, and reservoir storage values (own elaboration). 
For the comparative assessment, the actions that would have been taken on the 1 April each hydrological year have been compared using (i) the 2018 GRB DMP (i.e., based only on the reservoir storage volume and no information about the future), and (ii) AQUAFOR (i.e., using the mean streamflow forecast for the current hydrological year) in combination with the proposed water scarcity thresholds (described in Section 3.4). At the end of each hydrological year (1 October), when all the hydrological information is available, it can be assessed whether the measures activated back in April were actually required or not.

For this study, efficient strategies and actions are those that contribute towards optimizing the use of available water resources to meet the water demands of the system while minimizing environmental impacts (reduction of carbon footprint, the satisfaction of ecological flows, etc.) and reducing costs.

The Upper Genil River system uses an increasing hierarchy of SW resources and GW resources to meet the demand. Strategic GW resources are mainly used to satisfy UWSD. In this particular sub-basin, the SW resources from Canales and Quéntar reservoirs (from Sierra Nevada mountains) are of higher water quality than the GW from the aquifer and do not require any pumping system up to the potable water treatment plant. Therefore, in principle, minimising the use of GW resource would minimise the energy consumption (and carbon footprint) and energetic costs.

Figures 6 and 7 show the graphical monthly results, while Table 6 shows a summary of the main annual results in terms of (i) the volume of water consumed by each water user (in this case, the UWSD and the IWD) and from each available water source (in this case, from regulated SW resources and GW), and (ii) the water deficits (when the demand cannot be met) for each year of the historical data series used.

Table 6. Volume $\left(\mathrm{hm}^{3}\right)$ of water used and efficiency in satisfying the water demands.

\begin{tabular}{|c|c|c|c|c|c|c|c|c|c|c|c|c|}
\hline \multirow{3}{*}{$\begin{array}{c}\text { Hydrological } \\
\text { Year }\end{array}$} & \multicolumn{6}{|c|}{ S-I: Using the 2018 GRB DMP } & \multicolumn{6}{|c|}{$\begin{array}{c}\text { S-II: Using AQUAFOR } \\
\text { (Mean Streamflow Forecast) }\end{array}$} \\
\hline & \multicolumn{4}{|c|}{ UWSD } & \multicolumn{2}{|c|}{ IWD } & \multicolumn{4}{|c|}{ UWSD } & \multicolumn{2}{|c|}{ IWD } \\
\hline & SW & GW & Total & Deficit & SW & Deficit & SW & GW & Total & Deficit & SW & Deficit \\
\hline $2004 / 05$ & 35.46 & 2.06 & 37.52 & 0 & 25.90 & 0.00 & 37.52 & 0.00 & 37.52 & 0 & 25.90 & 0.00 \\
\hline $2005 / 06$ & 25.14 & 12.38 & 37.52 & 0 & 9.16 & 16.74 & 22.14 & 15.38 & 37.52 & 0 & 21.44 & 4.46 \\
\hline $2006 / 07$ & 23.14 & 14.38 & 37.52 & 0 & 14.88 & 11.02 & 19.14 & 18.39 & 37.52 & 0 & 14.74 & 11.16 \\
\hline $2007 / 08$ & 19.14 & 18.39 & 37.52 & 0 & 11.39 & 14.51 & 18.14 & 19.39 & 37.52 & 0 & 14.74 & 11.16 \\
\hline $2008 / 09$ & 26.14 & 11.38 & 37.52 & 0 & 25.90 & 0.00 & 37.52 & 0.00 & 37.52 & 0 & 25.90 & 0.00 \\
\hline Total & 129.02 & 58.60 & 187.62 & 0 & 87.25 & 42.27 & 134.46 & 53.16 & 187.62 & 0 & 102.73 & 26.79 \\
\hline Mean & 25.80 & 11.72 & 37.52 & 0 & 17.45 & $\begin{array}{c}8.45 \\
(33 \% *)\end{array}$ & 26.89 & 10.63 & 37.52 & 0 & 20.55 & $\begin{array}{c}5.36 \\
(21 \%) *\end{array}$ \\
\hline $\begin{array}{l}\text { Comparison } \\
\text { B/A }(\%)\end{array}$ & & & & & & & $4 \%$ & $-9 \%$ & $0 \%$ & & $18 \%$ & $-37 \%$ \\
\hline
\end{tabular}

* Mean annual water deficit for the IWD in relation to the total annual IWD of $25.904 \mathrm{hm}^{3}$ as established in the Guadalquivir RBMP 2015-2021. IWD: irrigation water demand; UWSD: urban water supply-demand. 
Projection: April

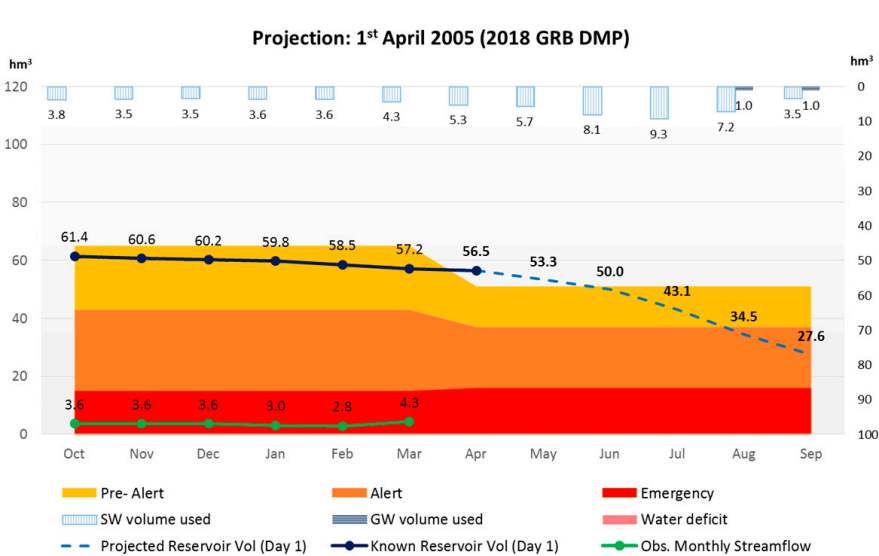

(a)

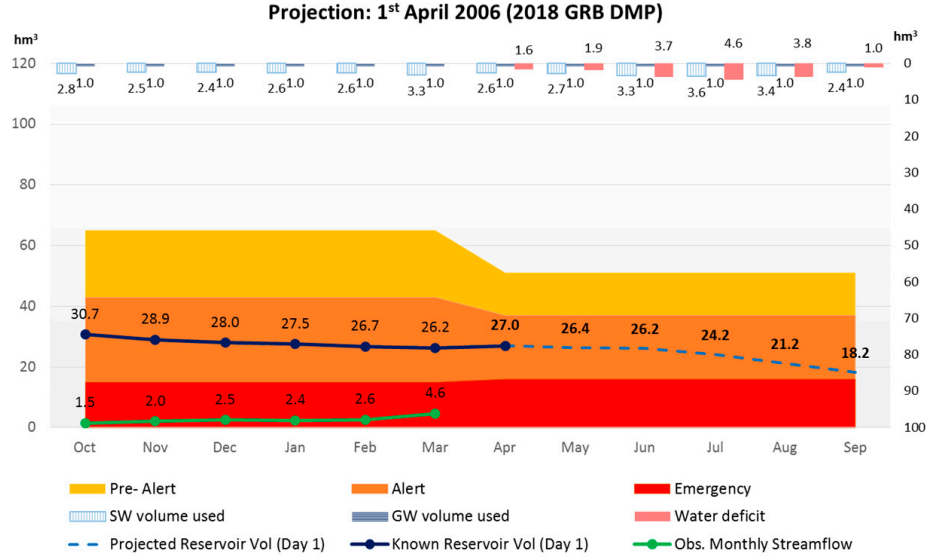

(c)
2005

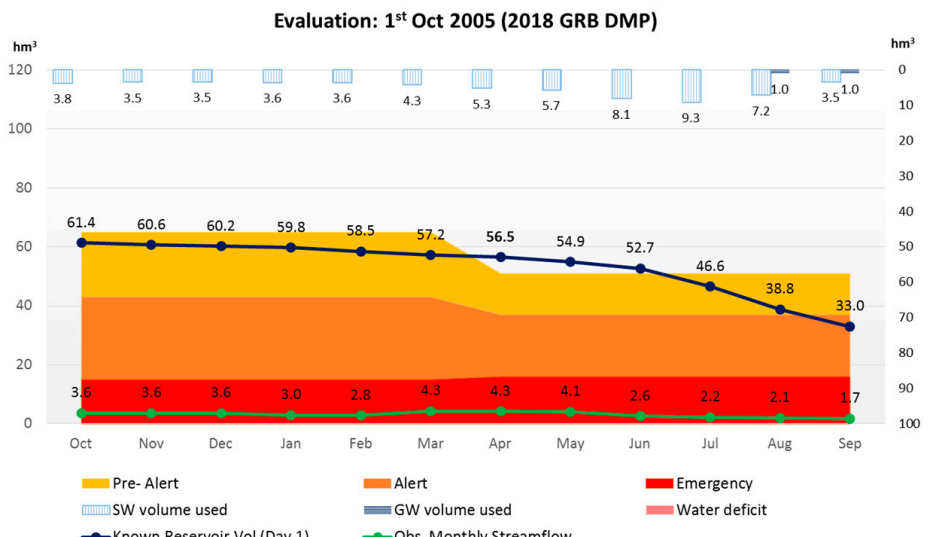

(b)

2006

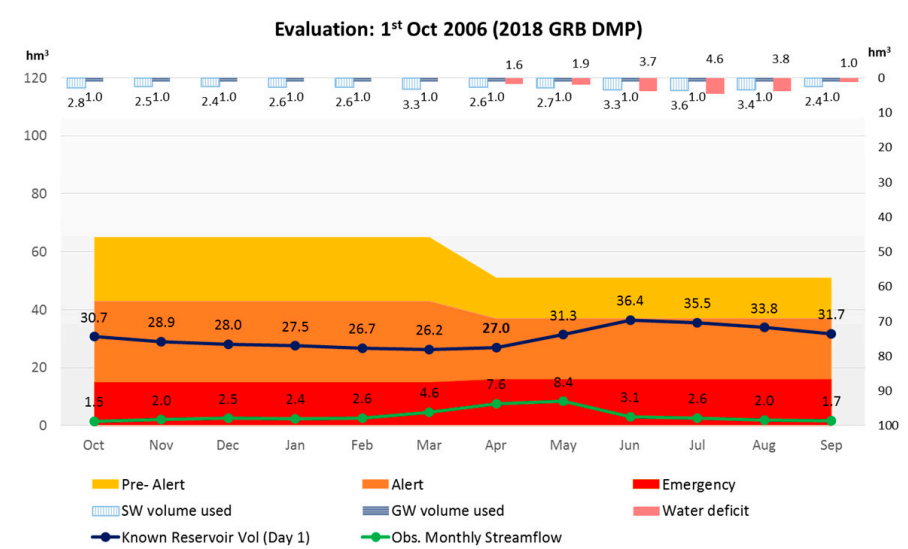

(d)

Figure 6. Cont. 
2007

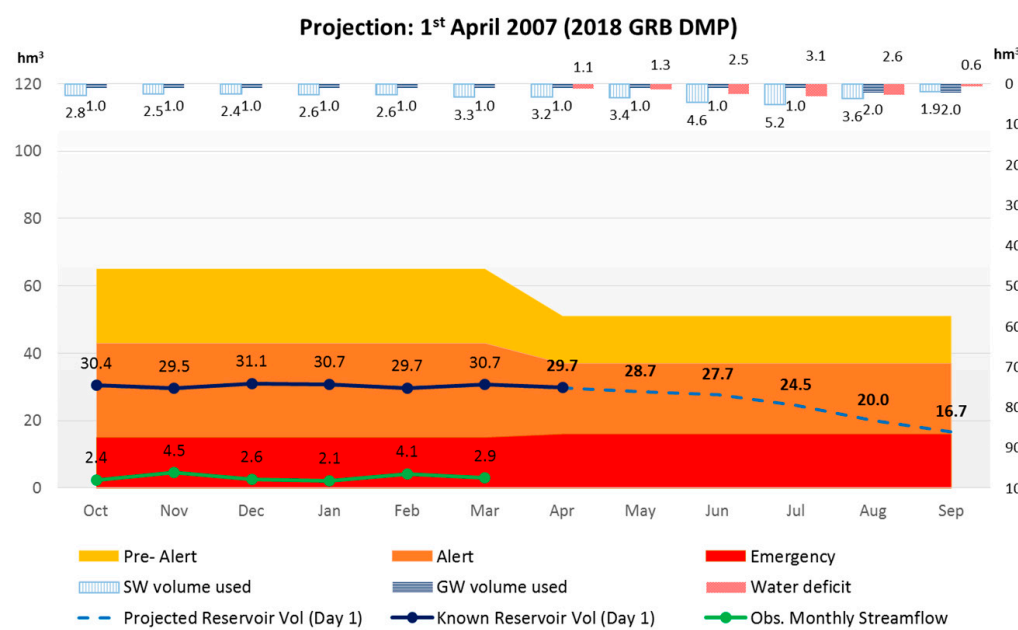

(e)

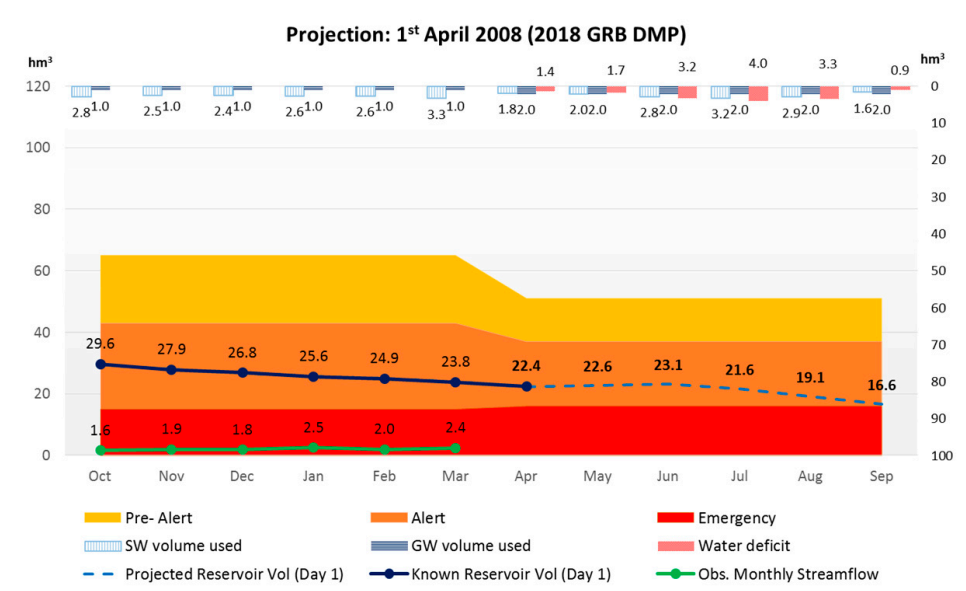

(g)

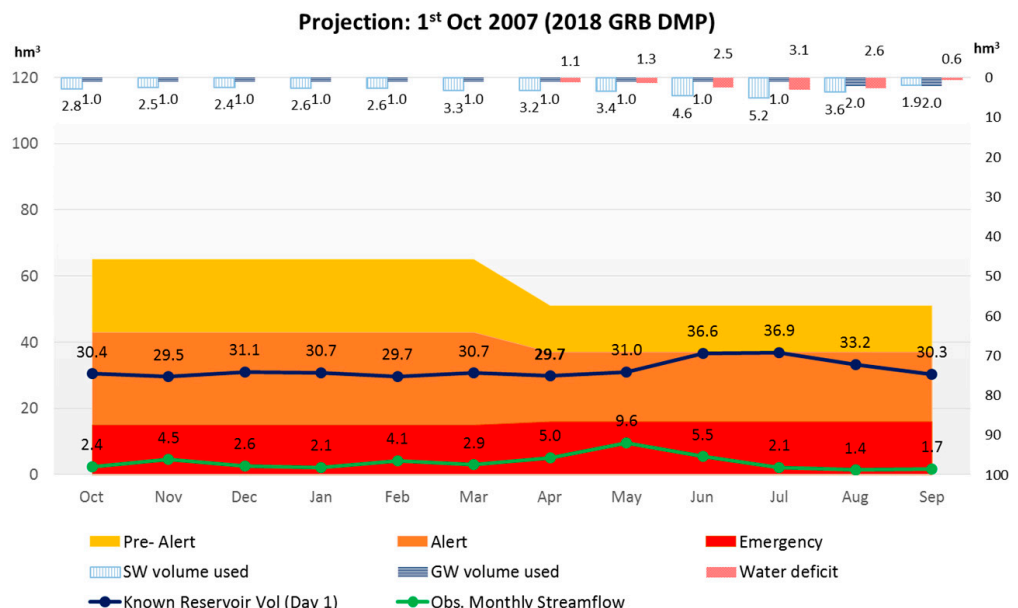

2008

$$
\text { (f) }
$$

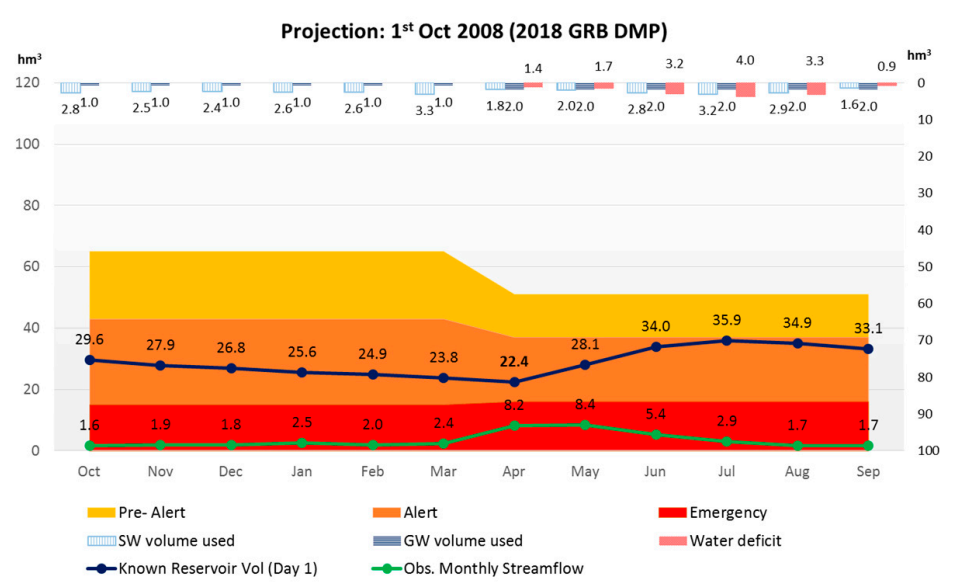

(h)

Figure 6. Cont. 


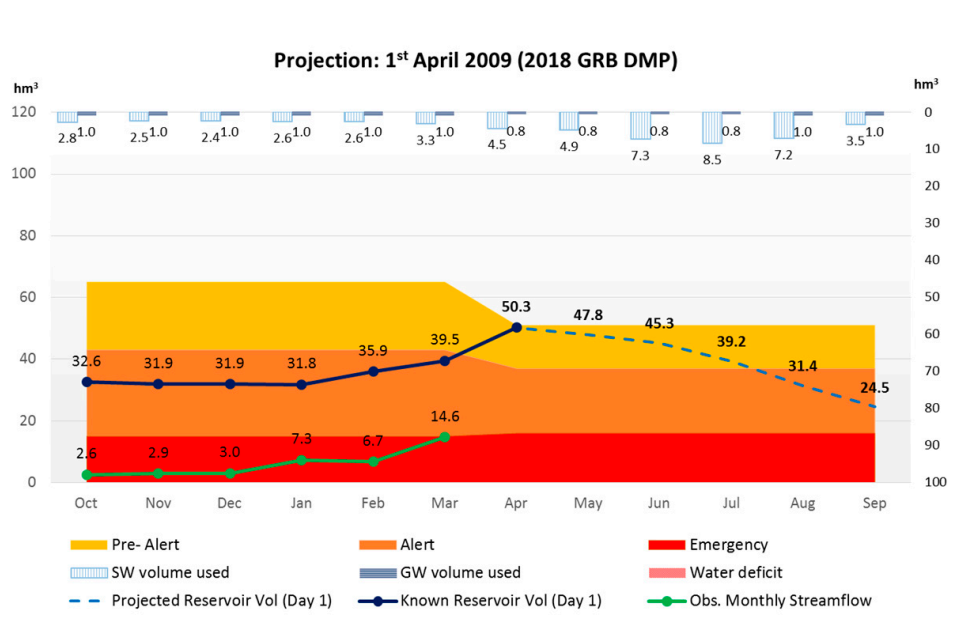

(i)
2009

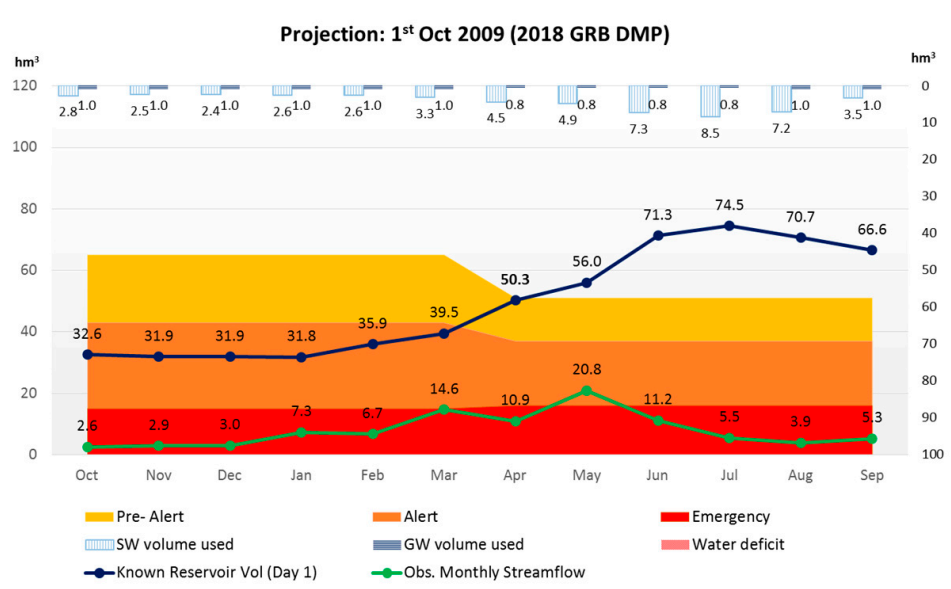

(j)

Figure 6. 2018 GRB DMP: Measures taken in April $(\mathbf{a}, \mathbf{c}, \mathbf{e}, \mathbf{g}, \mathbf{i})$ and evaluation of the real situation made in October $(\mathbf{b}, \mathbf{d}, \mathbf{f}, \mathbf{h}, \mathbf{j})$. 
Projection: April

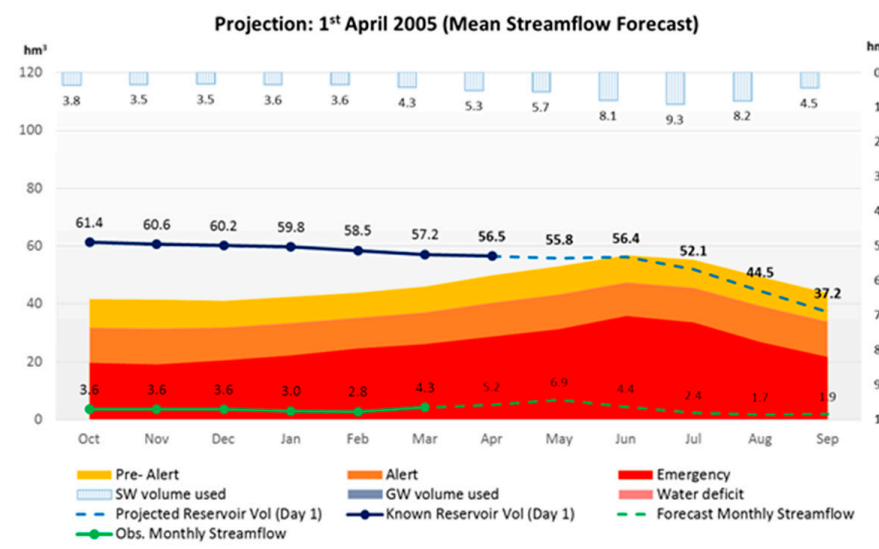

(a)

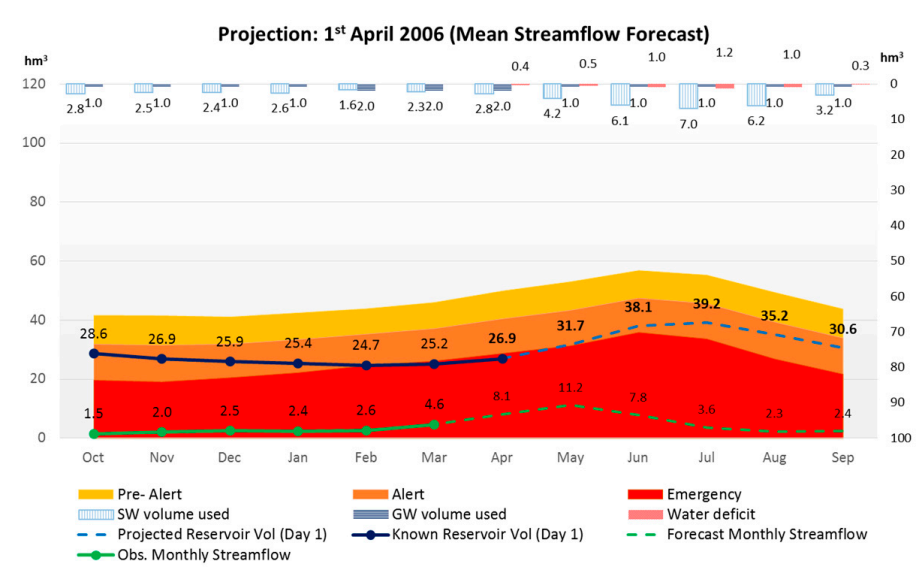

(c)

\section{Evaluation: October}

2005

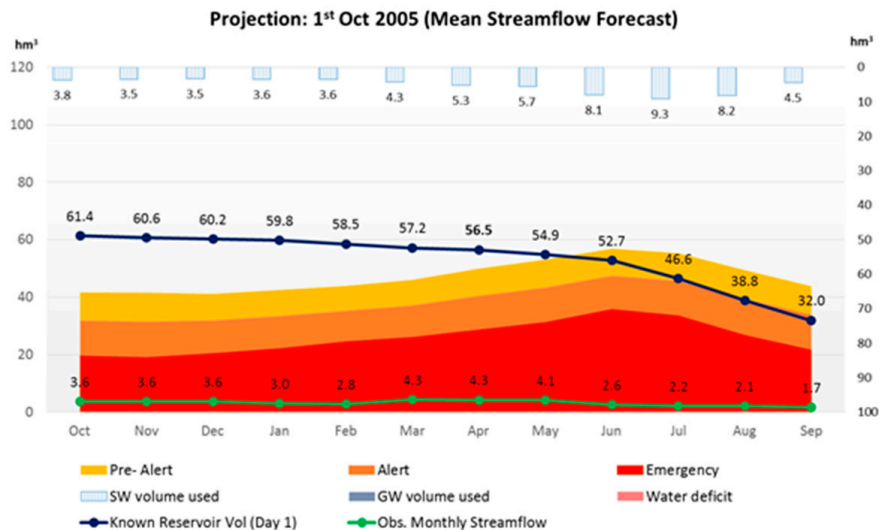

(b)

2006

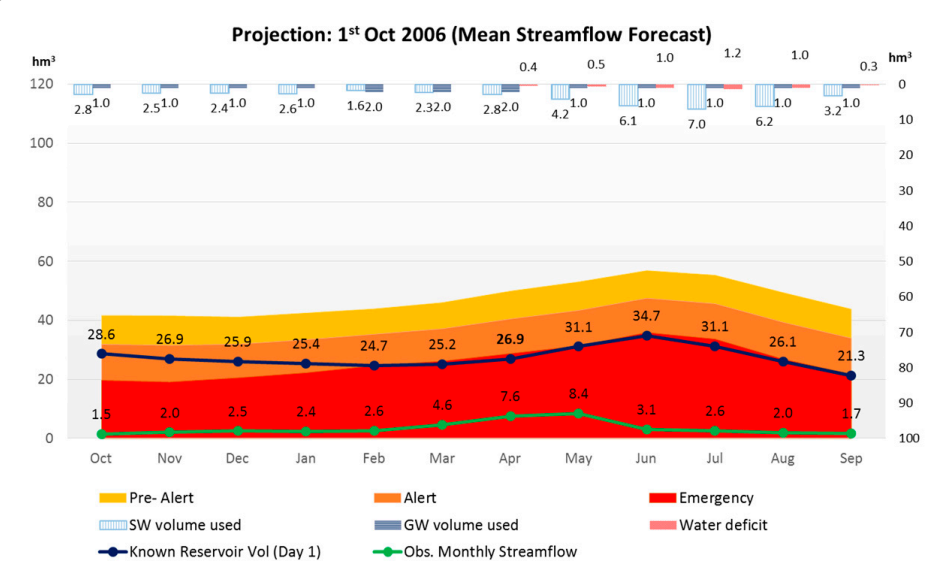

(d)

Figure 7. Cont. 
2007

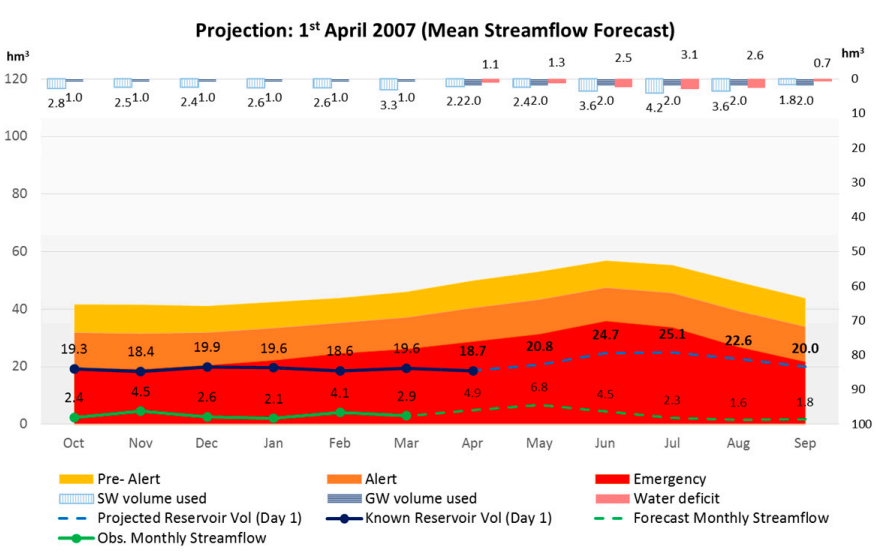

(e)

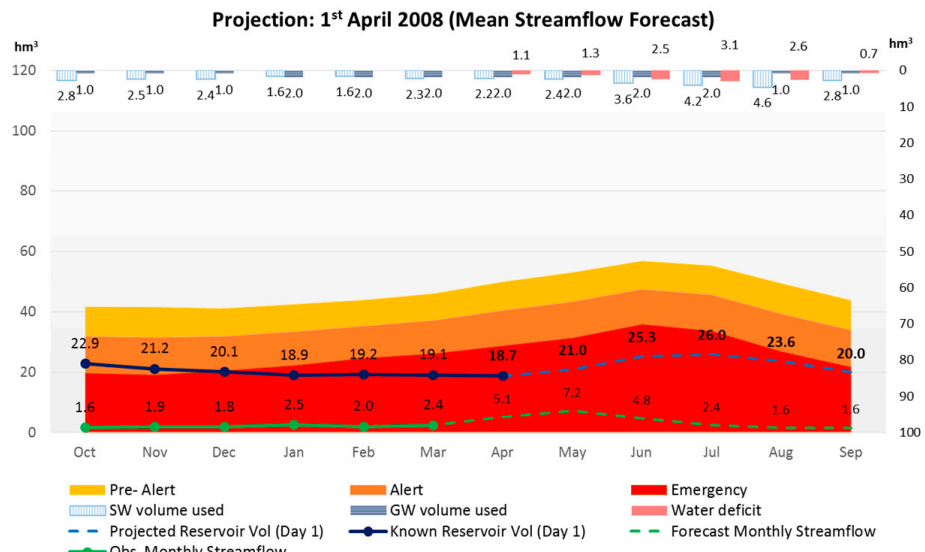

(g)

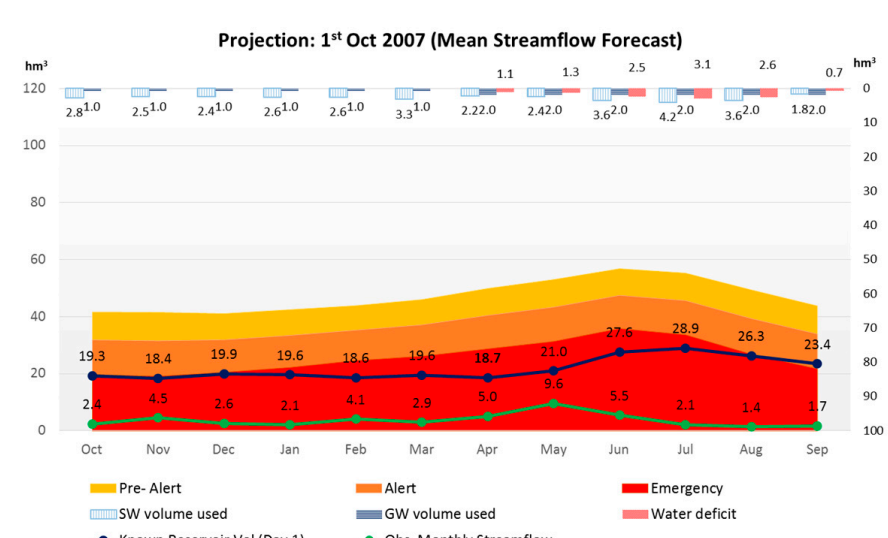

(f)

2008

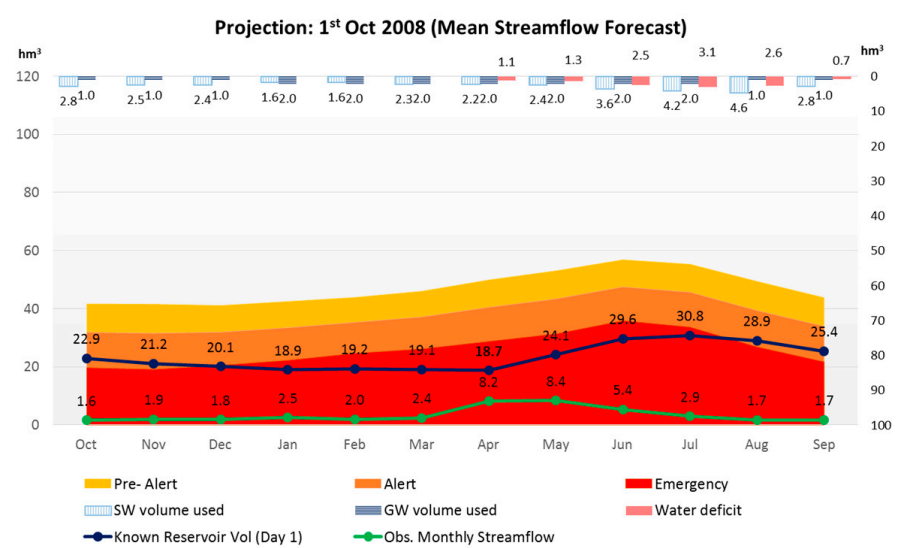

(h)

Figure 7. Cont. 


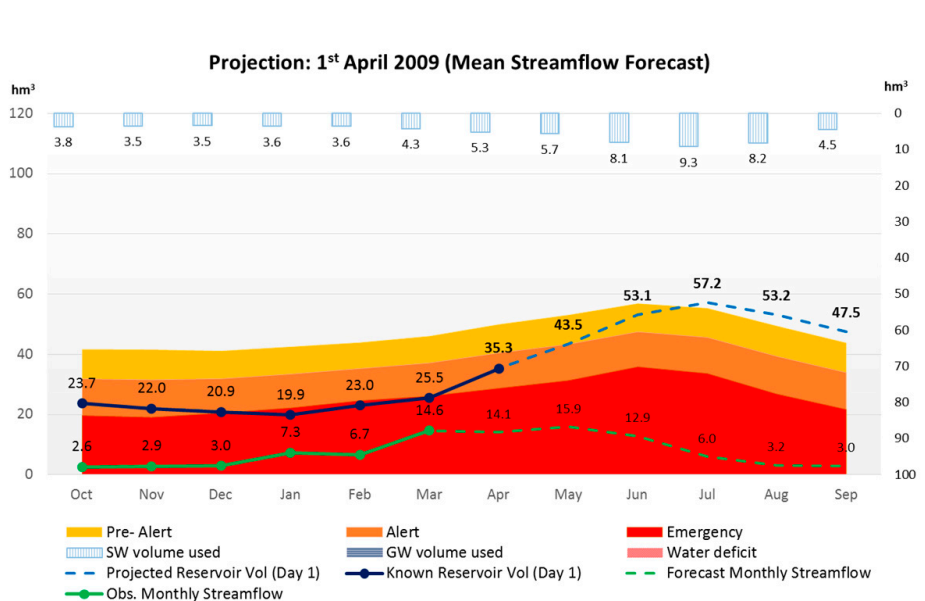

(i)

2009

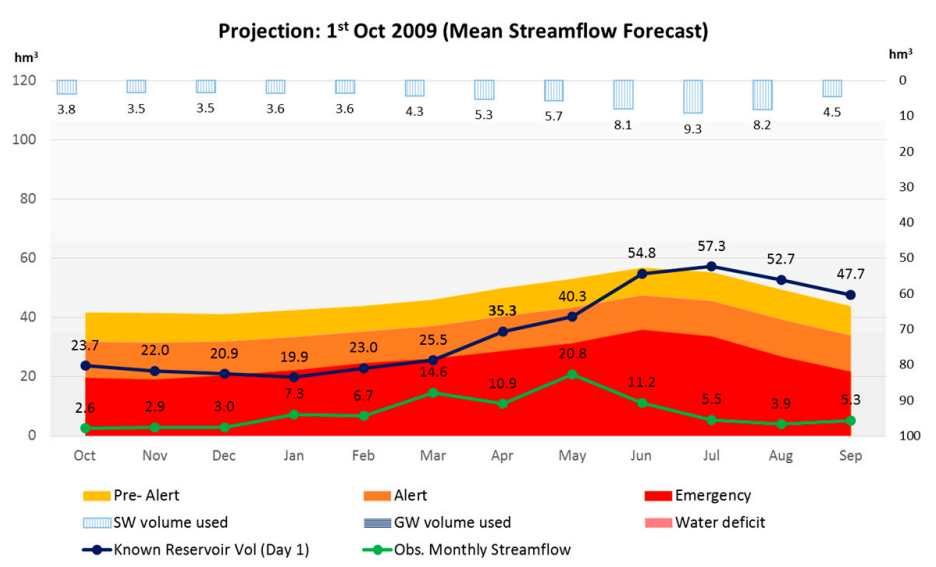

(j)

Figure 7. Using streamflow forecast models (in this case, AQUAFOR): Measures taken in April (a,c,e,g,i) and evaluation of the real situation made in October (b,d,f,h, $\mathbf{j})$. 
In both scenarios, the UWSD has been modeled with priority of water use over the IWD. The software used, input data, sources, and parameters of modeling are described in Appendix A.

If the results from S-I and S-II are compared, it can be appreciated how the optimal use and management of the existing available water resources of the system during a drought period that provides the greatest guarantee of supply for both, the UWSD and IWD, is achieved by using streamflow forecast tools (in this case, S-II Using AQUAFOR). Indeed, the water deficits of the system are considerably reduced (up to $37 \%$ for the IWD), and the use of strategic GW resources is minimized (up to $9 \%$ ). There is no water deficit for the UWSD in the whole drought period for S-I and S-II. The IWD benefits from a mean annual water deficit of $21 \%$ for S-II in comparison with $33 \%$ for S-I.

So, thanks to the better use of the existing SW resources (as shown in S-II):

- The carbon footprint can be minimized. A decrease in the GW volume consumed would, in principle, imply a reduction in the carbon footprint and economic costs (lower energy consumption due to the pumping requirements from the wells to the potable water treatment plant, as well as lower energy consumption for the potable water treatment requirements).

- Compliance with the ecological flow regime: The S-II model has been set out to satisfy the ecological flows before trying to meet the water demands of the system. Following the 2018 GRB DMP, there is the possibility of justifying a temporal deterioration of the ecological flow regime during a prolonged drought situation (for the particular case of study, this corresponds to the SPI-6month value lower than 1.49). Under this exceptional circumstance, the e-flows could be slightly reduced, and the urban water supply (households) has the highest priority of water use over any other water uses.

- Social consequences and economic losses due to the unnecessary water restrictions to the IWD can be avoided or, at least, considerably minimized.

The results from S-I show how the strategic GW water resources are activated much earlier in 2004/05 (shown in Table 6, Figure 6a,b) than for S-II (shown in Table 6, Figure 7a,b). Even after that, there are still considerable water deficits the following year (2006) in the IWD $\left(16.74 \mathrm{hm}^{3}\right.$, approximately $65 \%$ of the total annual IWD), as shown in Figure $6 \mathrm{c}, \mathrm{d}$.

It is important to note that before the drought event started (2004/05), the reservoir storage volume was relatively high in comparison with the mean historical year (as shown in Figure 5) and even in that situation, strategic GW resources would have been mobilized following the 2018 GRB DMP protocol.

The results from S-I show how the strategic GW water resources would have been activated all years (Figure 6a-j), in comparison with the results from S-II (Figure 7a-j) where the first and last year GW resources would have been activated (Figure 7a,i).

Equally important was the return-to-normal conditions (2008/09). The reservoir storage volume was relatively low (after the drought period); which was followed by an increasing level of rainfall. However, the 2018 GRB DMP would have been very slow in recognizing this change in the situation. Thus, even after months of rain, still, strategic GW resources would have been used (Figure 6i).

Although for the purposes of this comparative assessment, only the Mean Streamflow Forecast for the 1 April has been used, it is important to note that the AQUAFOR model provides monthly and yearly streamflow forecasts starting the forecasts from 1 January and then, monthly for the rest of the hydrological year. This can help improving the preparedness and planning the drought response, as well as to verify (on a monthly basis) what measures are required to be mobilised. So, in comparison with the 2018 GRB DMP, the use of forecasting models help in dealing with drought and water scarcity situations dynamically (say, every month), rather than statically (by deciding on April what is going to be done). 
Therefore, using streamflow forecasting models can help identifying more accurately the onset of the drought, the severity and return-to-normal conditions. This allows a better identification of when, how and what specific actions should be undertaken during a drought event, apart from providing more time to liaise with the required parties.

It is important to highlight that the 2018 GRB DMP water scarcity thresholds and actions have been established based on the 100-year return period drought event. Therefore, it is a relatively conservative plan, which might work well during severe and extreme drought events but less well during mild and moderate drought events (which are more frequent events). This means that during mild and moderate drought events, conservative measures could be applied (such as water restrictions to the IWD or mobilization of GW resources), that actually would not be required. These will have associated economic, environmental, and social consequences.

The results from S-II show how the use of streamflow forecast models can help with the early detection of droughts and water scarcity situations, identifying the adequate timing to activate and deactivate strategic water measures to ensure water supplies while minimizing social, environmental, and economic impacts. Therefore, the use of streamflow forecast models can support strategic water management decisions when deciding on optimum water allocation to achieve resource and cost-efficient strategies.

If droughts (and its severity) are foreseen with anticipation, it is more likely that sensible management strategies are designed by testing different risk scenarios, and consequently, optimal actions can be implemented (following, for example, a phased approach as the drought evolves). The risk-based forecast outputs can be also helpful to all water users and stakeholders involved in the planning, management, and decision-making processes.

\section{Concluding Remarks}

In Spain, the RBAs updated the DMPs in December 2017 (adopted in December 2018) at the river basin scale in the context of the WFD, as reported in the supplementary documents of the RBMPs (art. 13(5) WFD). The Guadalquivir is the main river in southern Spain, which periodically suffers the consequences of drought events and water scarcity episodes. One of the most pressing problems in this basin is precisely the fierce competition among water users for the scarce water resource.

The 2018 GRB DMP establishes the general drought-risk management principles, as well as the progressive implementation of actions based on the drought and water scarcity scenario. It is a well-structured report that contains the key elements of a DMP: (a) diagnosis system: territorial units and environmental characterization; (b) definition of a common global indicator and thresholds system (establishing onset, ending, and severity levels of the exceptional circumstances); (c) actions and measures to be taken in each phase; (d) organizational framework: monitoring and follow-up system to deal with drought and subsequent revision and updating of the existing DMP [15].

The 2018 GRB DMP clearly distinguishes drought events from water scarcity events, by setting out a different diagnosis system and measures to deal with each phenomenon separately. In fact, a common hydrological indicator system has been established to identify early enough and foresee the drought or water scarcity situations. This is to be applied in all river basins in Spain in compliance with the Spanish legislation.

The great advantage of this common indicator system is that despite the diverse climatic and geographical conditions in each individual basin, diagnosis results are comparable. So if a similar (drought or water scarcity) indicator value is found in two different sub-basins, the (drought or water scarcity) situation is expected to be similar, and the type of measures to be applied is expected to be of the same nature (preventive, operational or management of supply/demand, organizational, monitoring or recovery). 
This has helped to apply a consistent approach in terms of diagnosing a drought/water scarcity situation and provide clarity in terms of the type of actions to be taken to manage a drought and water scarcity situation. This highlights the important strides made by all the Spanish RBAs towards harmonization of technical procedures across all the river basins. This will not only provide support to the RBA decision-making processes (especially, when declaring formal drought situations) but also it will be very instructive when disseminating drought information to the general public. This demonstrates how a common indicator system at the EU level could be also possible.

Yet, doubts exist on a number of issues about the real effectiveness of the 2018 GRB DMP.

Firstly, general management measures proposed in the DMP should not disregard the inherent heterogeneity among the different water systems within the same basin (especially in those basins with historical and complex water rights interactions). Secondly, the proposed actions and measures are not supported by any technical, environmental, or economic assessments. These are fundamental to any DMP, so it can be demonstrated that the proposed actions and measures are sufficiently robust to achieve optimal use of existing water resources during a drought event that meets the water demands of the system while minimizing the economic, social, and environmental impacts of these actions.

Thirdly, the absence of using streamflow forecast models and seasonal climate forecasts is one of the greatest deficiencies in the current DMPs. The water scarcity thresholds and critical decisions on controlled released outflows from reservoirs are based on streamflow and precipitation probabilistic historical information only. Given the improvements in the accuracy and reliability of advanced hydrological information and streamflow forecasts, it is considered essential to use predictive models (at least for the current hydrological year) to anticipate and evaluate future impacts of a drought, as well as to take adequate and proportionate actions in each situation [20,31].

A comparative assessment has been carried out to assess how a water scarcity situation had been managed (i) following the 2018 GRB DMP protocol, and (ii) using a streamflow forecast model in combination with the proposed alternative water scarcity thresholds. The results show how the optimal use and management of the existing available water resources of the system during a drought period that provides the greatest guarantee of supply is achieved by using streamflow forecast tools. Indeed, the water deficits of the system are considerably reduced (up to 37\%), and the use of strategic GW resources is minimized (up to $9 \%$ ).

So, thanks to the better use of the existing SW resources using streamflow forecast tools: (i) the carbon footprint can be minimized, (ii) the compliance with the ecological flow regime can be better guaranteed and managed, and (iii) social consequences and economic losses due to the unnecessary water restrictions can be avoided or, at least, considerably minimized.

The use of streamflow forecast models can help with the early detection of droughts and water scarcity situations, identifying when and how actions should be implemented (timing to activate and deactivate strategic water measures) to ensure water supplies while minimizing social, environmental, and economic impacts. If droughts (and its severity) are foreseen with anticipation, it is more likely that sensible management strategies are designed by testing different risk scenarios, and consequently, optimal actions can be implemented.

The lessons learned could be applied to tackle water scarcity in other water-scarce and drought-prone basins.

Author Contributions: Draft version, research, calculations, editing, visualization, finalization, C.H.-G.; supervision, F.D.-R. All authors have read and agreed to the published version of the manuscript.

Funding: This research received no external funding.

Acknowledgments: The authors especially thank Hervás-Sánchez, D. for his help formatting the article, and Nathan Coles for his help revising the English style of some parts. The authors thank the reviewers and editor for the constructive comments which have helped to improve the quality of the manuscript.

Conflicts of Interest: The authors declare no conflict of interest.

Data Availability: All data has been made available at the time of submitting the draft manuscript. Should the editors or reviewers need any further information or clarification, please contact the corresponding author. 


\section{Abbreviations}

$\begin{array}{ll}\text { DMP } & \text { Drought Management Plan } \\ \text { Emasagra } & \text { Local Water and Sewage Company of Granada and metropolitan area } \\ \text { EU } & \text { European Union } \\ \text { GRB } & \text { Guadalquivir River Basin } \\ \text { GRBA } & \text { Guadalquivir River Basin Authority } \\ \text { GW } & \text { Ground Water } \\ \text { hm }^{3} & \text { cubic hectometre }\left(1 \mathrm{hm}^{3}=106 \mathrm{~m}^{3}\right) \\ \text { IWD } & \text { Irrigation Water Demand } \\ \text { RBA } & \text { River Basin Authority } \\ \text { RBMP } & \text { River Basin Management Plan } \\ \text { SW } & \text { Surface Water } \\ \text { TMU } & \text { Territorial Management Unit } \\ \text { UWSD } & \text { Urban Water Supply Demand } \\ \text { WFD } & \text { Water Framework Directive (Directive 2000/60/EC) }\end{array}$

\section{Appendix A. Upper Genil River Basin (Guadalquivir River Basin): Modeling Process, Input Data, Sources, and Limitations}

\section{Appendix A.1. AQUAFOR: Streamflow Forecast Model}

This is a simple, novel, user-guided, and low-cost methodology to forecast streamflows within the current hydrological year. It can be easily used by non-technical experts, such as water authorities, water managers, or water users. Therefore, it overcomes one of the major traditional limitations associated with the use of this kind of model.

The methodology was successfully applied to two headwater reservoirs within the Guadalquivir River Basin in southern Spain, achieving an accuracy of 92\% and 80\% in March 2017.

The model outputs are the probabilistic mean annual and monthly streamflows along with the 10th and 90th percentiles (which can be easily modified by the user, if needed).

The model results have been compared with the most recent ARIMA model results (for example, those shown in Myronidis et al. [32] and similar works cited by the same author). It has been found relevant that in average terms, our model performed similarly or even slightly better at providing results for even a longer forecasted period (for up to nine months in advance), using a much simpler methodology.

\section{Appendix A.2. AQUASPREAD: Model Simulation Process and Outcomes}

AquaSpread modeling software (developed by the University of Granada) has been used. This performs a volumetric balance on a monthly basis based on the headwater inflows, the reservoir storage volume variation, and the water outputs, such as the evapotranspiration, the environmental restrictions (e-flows), the water demands (urban water supply, irrigation, industry, energy), and the controlled released flood flows (where required). It also takes into account the available alternative water resources in the specific water exploitation system.

The model has been set out to satisfy the ecological flows of the system before trying to meet the water demands. Then, the model takes into account the priority of water use order assigned to each water user, as well as the preference order of the available water sources to serve each water demand.

The main outcomes from this modeling exercise are: (i) the volume of water consumed by each water user and from each available water source and (ii) the water deficits (when the demand cannot be met) for each month of the historical data series used.

\section{Appendix A.3. Input Data}

All the input data used to inform this study is publically available and described below.

\section{Appendix A.4. Surface Water Resources}

The 'Automatic Hydrological Information System (SAIH)' is a free and public online portal maintained by the Guadalquivir River Basin Authority (GRBA) in Spain [29]. The SAIH offers information, such as streamflow, rainfall, temperature, reservoir inflows, outflows, storage volume, and water level, for up to 57 reservoirs, 52 non-regulated rivers, 20 canals, and 10 hydropower plants. Other information on rain, snow, and temperature gauging stations across the basin is also offered. The available temporal data sets vary depending on the specific sub-catchment area. The information can be downloaded in an hourly, daily, or monthly time step or requested directly via an online application form or email to the SAIH contact details provided on the webpage [20].

The historical monthly streamflow data series for Canales (from October 1988 to present) and Quéntar (from October 1977 to present) have been obtained via an online request on the SAIH webpage. The common historical data set period for both reservoirs (1988/1989-2018/2019, 31 years) has been used in the modeling (included below for information). 
From the data set used, we would draw attention to the historical intense drought episodes: 1991-1995 and 2004-2008.

UPPER GENIL RIVER BASIN (QUÉNTAR RESERVOIR): Historical Monthly Streamflow Data Series (hm ${ }^{3}$ )

\begin{tabular}{|c|c|c|c|c|c|c|c|c|c|c|c|c|c|c|}
\hline$\frac{\text { Starting }}{\text { Year }}$ & $\frac{\text { Ending }}{\text { Year }}$ & Oct & Nov & Dec & Jan & Feb & Mar & Apr & May & Jun & Jul & Aug & Sep & Annual \\
\hline 1988 & 1989 & 1.00 & 1.07 & 1.01 & 0.92 & 1.90 & 1.68 & 2.33 & 1.73 & 1.19 & 0.71 & 0.61 & 0.81 & 14.94 \\
\hline 1989 & 1990 & 1.01 & 1.05 & 2.16 & 1.49 & 1.11 & 1.11 & 1.17 & 1.49 & 0.74 & 0.62 & 0.61 & 0.62 & 13.16 \\
\hline 1990 & 1991 & 1.02 & 1.12 & 1.17 & 1.13 & 1.00 & 2.83 & 1.66 & 1.09 & 0.85 & 0.65 & 0.62 & 0.84 & 13.97 \\
\hline 1991 & 1992 & 0.94 & 0.86 & 0.97 & 0.83 & 0.81 & 0.90 & 1.75 & 1.04 & 0.77 & 0.64 & 0.36 & 0.45 & 10.31 \\
\hline 1992 & 1993 & 0.83 & 0.75 & 1.03 & 0.66 & 0.58 & 1.14 & 0.82 & 1.38 & 0.59 & 0.48 & 0.57 & 0.35 & 9.19 \\
\hline 1993 & 1994 & 0.49 & 0.55 & 0.53 & 0.64 & 0.59 & 0.96 & 0.73 & 0.61 & 0.48 & 0.40 & 0.46 & 0.52 & 6.95 \\
\hline 1994 & 1995 & 1.01 & 0.36 & 0.59 & 0.51 & 0.44 & 0.56 & 0.40 & 0.34 & 0.38 & 0.27 & 0.21 & 0.24 & 5.32 \\
\hline 1995 & 1996 & 0.22 & 0.30 & 1.34 & 5.61 & 6.39 & 2.24 & 1.73 & 3.12 & 1.13 & 0.43 & 0.32 & 0.86 & 23.69 \\
\hline 1996 & 1997 & 0.90 & 0.91 & 4.76 & 10.00 & 3.64 & 2.38 & 2.16 & 1.56 & 1.11 & 0.57 & 0.65 & 1.03 & 29.67 \\
\hline 1997 & 1998 & 1.41 & 5.31 & 9.08 & \begin{tabular}{|l|}
4.36 \\
\end{tabular} & 3.74 & 2.51 & 2.38 & 3.02 & 1.97 & 1.03 & 0.69 & 0.88 & 36.38 \\
\hline 1998 & 1999 & 1.18 & 1.15 & 1.26 & 1.30 & 1.03 & 1.18 & 0.98 & 0.92 & 0.68 & 0.36 & 0.32 & 0.37 & 10.71 \\
\hline 1999 & 2000 & 0.64 & 0.60 & 0.83 & 0.69 & 0.70 & 0.47 & 1.05 & 1.51 & 0.79 & 0.35 & 0.26 & 0.24 & 8.13 \\
\hline 2000 & 2001 & 0.43 & 0.84 & 2.94 & 6.17 & 4.23 & 8.40 & 2.43 & 1.59 & 0.67 & 0.45 & 0.52 & 0.74 & 29.43 \\
\hline 2001 & 2002 & 1.28 & 1.26 & 1.42 & 1.10 & 0.76 & 1.43 & 2.30 & 1.31 & 0.62 & 0.60 & 0.46 & 0.55 & 13.09 \\
\hline 2002 & 2003 & 0.80 & 1.64 & 2.13 & 4.15 & 2.84 & 3.99 & 3.19 & 1.99 & 0.97 & 0.74 & 0.63 & 0.71 & 23.77 \\
\hline 2003 & 2004 & 1.05 & 1.55 & 1.63 & 1.46 & 1.29 & 1.48 & 2.80 & 4.43 & 1.96 & 1.03 & 0.83 & 0.78 & 20.28 \\
\hline 2004 & 2005 & 1.06 & 1.06 & 0.97 & 0.75 & 0.63 & 0.90 & 0.57 & 0.36 & 0.25 & 0.17 & 0.17 & 0.25 & 7.12 \\
\hline 2005 & 2006 & 0.35 & 0.45 & 0.79 & 0.85 & 0.94 & 1.62 & 1.32 & 1.02 & 0.70 & 0.62 & 0.38 & 0.46 & 9.48 \\
\hline 2006 & 2007 & 0.50 & 0.58 & 0.55 & 0.61 & 0.84 & 0.60 & 0.74 & 0.92 & 0.35 & 0.21 & 0.18 & 0.28 & 6.35 \\
\hline 2007 & 2008 & 0.31 & 0.49 & 0.72 & 0.85 & 0.53 & 0.50 & 1.07 & 0.89 & 0.38 & 0.23 & 0.18 & 0.19 & 6.33 \\
\hline 2008 & 2009 & 0.27 & 0.43 & 0.82 & 2.13 & 2.31 & 5.12 & 2.57 & 1.87 & 0.80 & 0.54 & 1.17 & 1.69 & 19.72 \\
\hline 2009 & 2010 & 2.25 & 1.58 & 4.80 & 10.84 & 11.70 & 12.77 & 4.56 & 2.62 & 1.58 & 0.95 & 0.88 & 0.88 & 55.39 \\
\hline 2010 & 2011 & 1.15 & 1.66 & 4.65 & 3.97 & 3.92 & 4.66 & 3.30 & 3.94 & 2.44 & 1.14 & 0.97 & 1.08 & 32.87 \\
\hline 2011 & 2012 & 1.13 & 1.50 & 1.24 & 1.24 & 0.85 & 0.95 & 1.34 & 1.25 & 0.62 & 0.48 & 0.33 & 0.53 & 11.43 \\
\hline 2012 & 2013 & 0.99 & 2.39 & 1.54 & 5.22 & 4.54 & 14.38 & 10.82 & 3.83 & 2.13 & 1.56 & 1.32 & 1.44 & 50.16 \\
\hline 2013 & 2014 & 1.34 & 1.19 & 1.50 & 2.09 & 4.43 & 5.20 & 2.76 & 1.83 & 1.13 & 1.24 & 1.16 & 1.20 & 25.05 \\
\hline 2014 & 2015 & 1.06 & 1.13 & 1.04 & 1.11 & 2.35 & 2.06 & 1.96 & 1.66 & 1.28 & 0.63 & 0.55 & 0.56 & 15.38 \\
\hline 2015 & 2016 & 0.71 & 0.75 & 0.74 & 0.83 & 1.69 & 1.47 & 1.81 & 1.61 & 0.88 & 0.74 & 0.78 & 0.77 & 12.76 \\
\hline 2016 & 2017 & 0.93 & 1.13 & 1.17 & 0.94 & 1.21 & 1.68 & 1.08 & 0.75 & 0.54 & 0.41 & 0.40 & 0.44 & 10.68 \\
\hline 2017 & 2018 & 0.59 & 1.00 & 1.32 & 1.30 & 1.01 & 15.21 & 7.51 & 3.66 & 1.93 & 1.05 & 1.14 & 1.25 & 36.98 \\
\hline 2018 & 2019 & 1.41 & 2.00 & 1.34 & 1.15 & 1.70 & 1.21 & 2.06 & 1.56 & 1.04 & 0.72 & 0.89 & 1.01 & 16.11 \\
\hline
\end{tabular}

Figure A1. Historical monthly streamflow data series $\left(\mathrm{hm}^{3}\right)$ for Canales and Quéntar reservoirs (October 1988-September 2019).

\section{Appendix A.5. Groundwater Resources}

For the chosen case of study, the GW resources relate to the available abstraction capacity of the existing network of operating wells located in the upper area of the Vega de Granada aquifer (known as "Pozos de la Ronda Sur"). This source supplements the regulated SW resources and is normally used to supply the UWSD of Granada and its metropolitan area. The maximum extraction capacity is $2 \mathrm{hm}^{3} /$ month.

Although the technical pump capacity of the wells is slightly greater than $2 \mathrm{hm}^{3} / \mathrm{month}$, this amount has been set out as the maximum value for modeling purposes (and to be used only when needed). The two reasons that support this assumption are: (i) a maximum abstraction capacity of $2 \mathrm{hm}^{3} /$ month is in line with the protocol of actions and measures during drought and water scarcity situations established by the recently approved in December 2018 GRB drought management plan (DMP) [18]; (ii) this value is validated with the historical monthly maximum abstraction of $2.44 \mathrm{hm}^{3} /$ month (June 2008) and the annual historical maximum of $18 \mathrm{hm}^{3} /$ year (2008).

Appendix A.6. Ecological Flows (e-flows)

Ecological flows have been taken from the Guadalquivir RBMP (2015-2021) [18], as shown in Table A1.

Table A1. Ecological flows.

\begin{tabular}{|c|c|c|c|c|c|c|c|c|c|c|c|c|c|}
\hline \multirow{2}{*}{ Reservoir } & \multicolumn{13}{|c|}{ Volume $\left(\mathrm{hm}^{3}\right)$} \\
\hline & Oct & Nov & Dec & Jan & Feb & Mar & Apr & May & Jun & Jul & Aug & Sep & TOTAL \\
\hline Canales & 0.308 & 0.298 & 0.388 & 0.388 & 0.351 & 0.388 & 0.376 & 0.295 & 0.285 & 0.295 & 0.295 & 0.285 & 3.952 \\
\hline Quéntar & 0.134 & 0.130 & 0.134 & 0.134 & 0.121 & 0.134 & 0.130 & 0.134 & 0.130 & 0.134 & 0.134 & 0.130 & 1.577 \\
\hline
\end{tabular}

Note: the number of decimal places shown in Tables A1-A4 is in accordance with the Guadalquivir RBMP (2015-2021) from Guadalquivir RBMP (2015-2021).

In Spain, the Q eco is not considered as a water demand but as a water restriction (or water constraint). This means that ecological flows must be satisfied in the first instance prior to meeting the water demands of the system in all situations, except when there is a prolonged drought scenario (for the particular case of study, this corresponds to SPI's 6-month values lower than 1.49). Under this exceptional circumstance, the e-flows could be 
slightly reduced, and the urban water supply (households) has the highest priority of water use over any other water uses.

\section{Appendix A.7. Established Water Demands (UWSD and IWD)}

For modeling purposes, the water demands established in the Guadalquivir RBMP (2015-2021) have been taken, as shown in Table A2. It is important to note that these water demands are not real water consumption values but estimations made by the RBA.

The UWSD is named as "UDU 06A01 Área Metropolitana Granada Genil" and is formed by Granada city and its metropolitan area (14 towns). The established total annual UWSD is $37.524 \mathrm{hm}^{3}$, with a constant monthly UWSD of $3.13 \mathrm{hm}^{3}$.

The IWD is named as "06D02-Regadíos Vega Alta río Genil" and is formed by various irrigation communities with a total irrigated land of approximately 3800 ha (according to the Guadalquivir RBMP (2015-2021)). The established annual water demand is $25.9 \mathrm{hm}^{3}$, with the peak water demand in summer months (June, July, and August).

In this case, it is important to highlight that there has been a progressive reduction in the total irrigated land during the past decades, mainly due to urban development and new infrastructures. However, this reduction in the irrigated land (and a corresponding reduction in water demand) has not been integrated yet in the water demands estimations made by the GRBA.

Table A2. Established water demands from Guadalquivir RBMP (2015-2021).

\begin{tabular}{|c|c|c|c|c|c|c|c|c|c|c|c|c|c|}
\hline \multirow{2}{*}{$\begin{array}{c}\text { Name (from the } \\
\text { Guadalquivir RBMP) }\end{array}$} & \multicolumn{13}{|c|}{ Water Demand $\left(\mathrm{hm}^{3}\right)$} \\
\hline & Oct & Nov & Dec & Jan & Feb & Mar & Apr & May & Jun & Jul & Aug & Sep & TOTAL \\
\hline $\begin{array}{c}\text { UDU } 0601 \text { Área Metropolitana } \\
\text { de Granada-Genil } \\
\text { UDA 06D02. Regadios }\end{array}$ & 3.127 & 3.127 & 3.127 & 3.127 & 3.127 & 3.127 & 3.127 & 3.127 & 3.127 & 3.127 & 3.127 & 3.127 & 37.524 \\
\hline $\begin{array}{c}\text { Tradicionales Vega Alta } \\
\text { río Genil }\end{array}$ & 0.658 & 0.391 & 0.338 & 0.507 & 0.507 & 1.181 & 2.134 & 2.578 & 4.997 & 6.129 & 5.106 & 1.378 & 25.904 \\
\hline
\end{tabular}

Note: the number of decimal places shown in Tables A1-A4 is in accordance with the Guadalquivir RBMP (2015-2021) from Guadalquivir RBMP (2015-2021).

The peak water demand occurs in summer months, when the temperature is higher, evaporation is higher, and precipitation is lower. This puts large amounts of pressure on water resources (quantity and quality) and highlights the relevance of reservoirs to better manage the irregularity in precipitation in relation to the demand pattern (as well as to deal with the effects of extreme hydrological and climate phenomena).

\section{Appendix A.8. Minimum and Maximum Storage Volume Reservoirs}

This information has been also taken from the Guadalquivir RBMP (2015-2021) and shown in Tables A3 and A4.

The maximum storage volume is related to the maximum storage capacity of reservoirs (October-November, and May-September) and the flood protection function of reservoirs (from December to April).

Table A3. Minimum monthly reservoir storage volume requirements from Guadalquivir RBMP (2015-2021).

\begin{tabular}{lcccccccccccc}
\hline \multirow{2}{*}{ Reservoir } & \multicolumn{10}{c}{ Volume $\left.\mathbf{( h m}^{\mathbf{3}}\right)$} \\
\cline { 2 - 14 } & Oct & Nov & Dec & Jan & Feb & Mar & Apr & May & Jun & Jul & Aug & Sep \\
\hline Canales & 5.00 & 5.00 & 5.00 & 5.00 & 5.00 & 5.00 & 5.00 & 5.00 & 5.00 & 5.00 & 5.00 & 5.00 \\
Quéntar & 2.00 & 2.00 & 2.00 & 2.00 & 2.00 & 2.00 & 2.00 & 2.00 & 2.00 & 2.00 & 2.00 & 2.00 \\
\hline
\end{tabular}

Note: the number of decimal places shown in Tables A1-A4 is in accordance with the Guadalquivir RBMP (2015-2021) from Guadalquivir RBMP (2015-2021).

Table A4. Maximum monthly reservoir storage volume from Guadalquivir RBMP (2015-2021).

\begin{tabular}{ccccccccccccc}
\hline \multirow{2}{*}{ Reservoir } & \multicolumn{10}{c}{ Volume $\mathbf{( h m}^{\mathbf{3}}$ ) } \\
\cline { 2 - 13 } & Oct & Nov & Dec & Jan & Feb & Mar & Apr & May & Jun & Jul & Aug & Sep \\
\hline Canales & 70.0 & 70.0 & 59.4 & 58.6 & 57.9 & 61.5 & 68.6 & 70.0 & 70.0 & 70.0 & 70.0 & 70.0 \\
Quéntar & 13.6 & 13.6 & 11.4 & 11.3 & 11.1 & 11.8 & 13.2 & 13.6 & 13.6 & 13.6 & 13.6 & 13.6 \\
\hline
\end{tabular}

Note: the number of decimal places shown in Tables A1-A4 is in accordance with the Guadalquivir RBMP (2015-2021) from Guadalquivir RBMP (2015-2021). 


\section{Appendix B. 2018 GRB DMP-Proposed Measures to Be Applied to the Upper Genil River Basin}

Table A5. Upper Genil River System: Specific actions and measures proposed in the 2018 GRB DMP to be applied in each water scarcity scenario (own elaboration, data from 2018 GRB DMP).

\begin{tabular}{|c|c|c|c|}
\hline Water Scarcity Scenario & Type of Measure to Apply & Time & Authority \\
\hline Normal & Track and monitor the water scarcity index & Monthly & GRB Authority \\
\hline \multirow{5}{*}{ Pre-Alert } & Track and monitor the water scarcity index & Any month & GRB Authority \\
\hline & Raise awareness campaigns and promote voluntary actions of temporary water savings. & Any month & $\begin{array}{l}\text { GRB Authority and Local Water } \\
\text { Authority }\end{array}$ \\
\hline & $\begin{array}{l}\text { Inventory, updating and maintenance of specific infrastructures to deal with a potential } \\
\text { water scarcity situation. Inspection and adaptation of existing groundwater intakes. }\end{array}$ & Any month & $\begin{array}{l}\text { GRB Authority and Local Water } \\
\text { Authority }\end{array}$ \\
\hline & $\begin{array}{l}\text { Assess the possibility of providing up to } 8 \mathrm{hm}^{3} / \text { year (distributed in at least } 6 \text { months) to } \\
\text { supply the UWSD from the strategic underground wells. }\end{array}$ & Any month & $\begin{array}{l}\text { GRB Authority and Local Water } \\
\text { Authority }\end{array}$ \\
\hline & Assess the opportunity to advise crops with lower water demands. & October-March & GRB Authority \\
\hline \multirow{9}{*}{ Alert } & Track and monitor the water scarcity index & Any month & GRB Authority \\
\hline & $\begin{array}{l}\text { Apply water reduction measures to the UWSD (goal: } 5 \% \text { ). Activation of water savings } \\
\text { plans for large urban consumers and water restrictions on non-essential urban water uses } \\
\text { (garden irrigation, street cleaning activities, etc.). }\end{array}$ & Any month & $\begin{array}{l}\text { GRB Authority and Local Water } \\
\text { Authority }\end{array}$ \\
\hline & Activate education and water saving awareness campaigns. & Any month & $\begin{array}{l}\text { GRB Authority and Local Water } \\
\text { Authority }\end{array}$ \\
\hline & $\begin{array}{l}\text { Verificate that the Alert level of the Operational and Contingency DMPs for urban water } \\
\text { supply systems has been activated }\end{array}$ & Any month & Local Water Authority \\
\hline & Increase the control of the piezometric levels as well as the Deifontes Spring flows & Any month & GRB Authority \\
\hline & $\begin{array}{l}\text { Mobilise strategic GW resources: } \\
- \text { Up to } 12 \mathrm{hm}^{3} / \text { year to supply the UWSD } \\
\text { - Up to } 2.5 \mathrm{hm}^{3} / \text { year year to supply the IWD }\end{array}$ & Any month & $\begin{array}{c}\text { GRB Authority and Local Water } \\
\text { Authority }\end{array}$ \\
\hline & $\begin{array}{l}\text { Recommendation to the Exploitation Service to assess whether it may be convenient to } \\
\text { reduce the water volume allocated to the IWD to face the irrigation campaign. The } \\
\text { objective is to schedule the reservoir outflow releases to achieve a minimum reservoir } \\
\text { volume at the end of the irrigation campaign of at least } 16 \mathrm{hm}^{3} \text { in Quéntar and Canales } \\
\text { reservoirs, and of at least } 6 \mathrm{hm}^{3} \text { in Cubillas and Colomera reservoirs. }\end{array}$ & October to March & GRB Authority \\
\hline & $\begin{array}{l}\text { Ask the Water Commission and the Exploitation Service to maintain special vigilance for } \\
\text { water flow detractions for irrigation. }\end{array}$ & April to September & GRB Authority \\
\hline & $\begin{array}{l}\text { Assess the option to reduce unregulated irrigation water demands and reduce the use of } \\
\text { GW resources for irrigation. The objective will be to maintain a strategic groundwater } \\
\text { reserve for possible mobilizations if necessary }\end{array}$ & April to September & GRB Authority \\
\hline
\end{tabular}


Table A5. Cont.

\begin{tabular}{|c|c|c|c|}
\hline Water Scarcity Scenario & Type of Measure to Apply & Time & Authority \\
\hline \multirow{10}{*}{ Emergency } & Track and monitor the water scarcity index & Any month & GRB Authority \\
\hline & Intensify education and water saving awareness campaigns. & Any month & $\begin{array}{l}\text { GRB Authority and Local Water } \\
\text { Authority }\end{array}$ \\
\hline & $\begin{array}{l}\text { Mobilise strategic GW resources: } \\
\text { - Up to } 24 \mathrm{hm}^{3} / \text { year to supply the UWSD } \\
\text { - Up to } 5 \mathrm{hm}^{3} / \text { year to supply the IWD }\end{array}$ & Any month & $\begin{array}{l}\text { GRB Authority and Local Water } \\
\text { Authority }\end{array}$ \\
\hline & Intensify water reduction measures to the UWSD (minimum $5 \%$, and goal $10 \%$ ). & Any month & $\begin{array}{l}\text { GRB Authority and Local Water } \\
\text { Authority }\end{array}$ \\
\hline & $\begin{array}{c}\text { Verificate that the Emergency level of the Operational and Contingency DMPs for urban } \\
\text { water supply systems has been activated }\end{array}$ & Any month & Local Water Authority \\
\hline & Increase the control of the piezometric levels as well as the Deifontes Spring flows & Any month & GRB Authority \\
\hline & $\begin{array}{l}\text { Enable the Exploitation Service to reduce the water volume allocated to the IWD to face the } \\
\text { irrigation campaign. The objective is to schedule the reservoir outflow releases to achieve a } \\
\text { minimum reservoir volume at the end of the irrigation campaign of at least } 16 \mathrm{hm}^{3} \text { in } \\
\text { Quéntar and Canales reservoirs, and of at least } 6 \mathrm{hm}^{3} \text { in Cubillas and Colomera reservoirs. }\end{array}$ & October to March & GRB Authority \\
\hline & $\begin{array}{l}\text { Water restrictions to irrigation, except in exceptional cases, with the objective of reaching a } \\
\text { volume greater than } 16 \mathrm{hm}^{3} \text { in Quentar and Canales reservoirs, and a volume greater than } \\
\qquad 6 \mathrm{hm}^{3} \text { in Cubillas and Colomera reservoirs. }\end{array}$ & April to September & GRB Authority \\
\hline & $\begin{array}{l}\text { Ask the Water Commission and the Exploitation Service to maintain special vigilance for } \\
\text { water flow detractions for irrigation. }\end{array}$ & April to September & GRB Authority \\
\hline & $\begin{array}{l}\text { Assess the option to reduce unregulated irrigation water demands and reduce the use of } \\
\text { GW resources for irrigation. The objective will be to maintain a strategic groundwater } \\
\text { reserve for possible mobilizations if necessary }\end{array}$ & April to September & GRB Authority \\
\hline
\end{tabular}




\section{References}

1. Masson-Delmotte, V.; Zhai, P.; Pörtner, H.-O.; Roberts, D.; Skea, J.; Shukla, P.R.; Pirani, A.; Moufouma-Okia, W.; Péan, C.; Pidcock, R.; et al. IPCC, 2018: Summary for Policymakers. In Global Warming of 1.5 _C; An IPCC Special Report on the Impacts of Global Warming of 1.5_C above Pre-Industrial Levels and Related Global Greenhouse Gas Emission Pathways, in the Context of Strengthening the Global; Intergovernmental Panel on Climate Change (IPPC): Geneva, Switzerland, 2018. Available online: https://www.ipcc.ch/sr15/chapter/spm/ (accessed on 10 January 2019).

2. Schmidt, G.; Benítez, J.J.; Benítez, C. Working Definitions of Water Scarcity and Drought Report; TYPSA Intecsa-Inarsa: Madrid, Spain, 2012.

3. EC. Water Scarcity and Drought in the European Union-Environment-European Commission 2019. Available online: http://ec.europa.eu/environment/water/quantity/scarcity_en.htm?cookies=disabled (accessed on 15 January 2019).

4. EEA. Climate Change, Impacts and Vulerability in Europe 2016. An Indicator-Based Report; European Envitonment Agency: Copenhagen, Denmark, 2016; ISBN 978-92-9213-835-6.

5. EEA. Climate Change Poses Increasingly Severe Risks for Ecosystems, Human Health and the Economy in Europe; European Envitonment Agency: Copenhagen, Denmark, 2017.

6. Hervás-Gámez, C.; Delgado-Ramos, F. Drought Management Planning Policy: From Europe to Spain. Sustainability 2019, 11, 1862. [CrossRef]

7. European Parliament and Council of the European Union. Directive 2000/60/EEC of the European Union and of the Council of 23 October 2000 establishing a framework for community action in the field of water policy. Off. J. Eur. Communities 2000, L327, 2000.

8. EC. Addressing the Challenge of Water Scarcity and Droughts in the European Union; no. COM (2007) 414, 18.07.07; Environmental Policy Document Catalogue; Commission of the European Communities: Brussels, Belgium, 2007.

9. EC. First Follow up Report to the Communication on Water Scarcity and Droughts in the European Union COM (2007) 414 Final. Brussels, 19.12.2008 COM (2008) 875 Final; Commission of the European Communities: Brussels, Belgium, 2008.

10. EC. Second Follow up Report to the Communication on Water Scarcity and Droughts in the European Union 18.5.2010 COM (2010) 228 Final; Commission of the European Communities: Brussels, Belgium, 2010.

11. EC. Third Follow up Report to the Communication on Water Scarcity and Droughts in the European Union COM (2007) 414 Final SEC(2011) 338 Final; Commission of the European Communities: Brussels, Belgium, 2011.

12. EC. Commission Communication on the Report on the Review of the European Water Scarcity and Droughts Policy, Adopted together with the Blueprint; COM(2012) 672, 14.11.2012, no. SWD(2012) 380 final EN; Commission of the European Communities: Brussels, Belgium, 2012.

13. EC. A Blueprint to Safeguard Europe's Water Resources. Communication from the Commission to the European Parliament, the Council, the European Economic and Social Committee and the Committee of the Regions; Commission of the European Communities: Brussels, Belgium, 2012.

14. Global Water Partnership Central and Eastern Europe. Guidelines for preparation of the Drought Management Plans. 2015. Available online: http://www.droughtmanagement.info/literature/GWPCEE_Guidelines_ Preparation_Drought_Management_Plans_2015.pdf (accessed on 15 February 2019).

15. European Commission. Drought Management Plan Report Including Agricultural, Drought Indicators and Climate Change Aspects Water Scarcity and Droughts Expert Network; European Commission: Luxembourg, 2007. Available online: http://www.droughtmanagement.info/literature/GWPCEE_Guidelines_Preparation_ Drought_Management_Plans_2015.pdf (accessed on 5 February 2019).

16. Spanish Ministry for the Ecological Transition. Planes de Gestión de Sequías. 2019. Available online: https://www.miteco.gob.es/es/agua/temas/observatorio-nacional-de-la-sequia/planificacion-gestionsequias/ (accessed on 15 January 2019).

17. MAPAMA. Ministerio de Agricultura, Pesca y Alimentación. 2007. Available online: https://www.mapa.gob. es/es/ministerio/default.aspx (accessed on 23 March 2019).

18. Guadalquivir River Basin Authority. Guadalquivir River Basin-Drought Management Plan. 2018. Available online: http://www.chguadalquivir.es/plan-de-sequia-vigente\#PlanesEspecialesdeSequiavigentes (accessed on 15 January 2019). 
19. Guadalquivir River Basin Authority. General Information Guadalquivir River Basin. 2019. Available online: http://www.chguadalquivir.es/la-demarcacion-hidrografica-del-guadalquivir (accessed on 16 January 2019).

20. Delgado-Ramos, F.; Hervas-Gamez, C. Simple and Low-Cost Procedure for Monthly and Yearly Streamflow Forecasts during the Current Hydrological Year. Water 2018, 10, 26. [CrossRef]

21. CEDEX. Caracterización Hidrológica de Sequias; Ministerio de Agricultura, Alimentación y Medio Ambiente. Secretaría de Estado de Medio Ambiente. Dirección General del Agua. Gobierno de España: Madrid, Spain, 2013. Available online: http://www.cedex.es/CEDEX/LANG_CASTELLANO/ (accessed on 16 January 2019).

22. CEDEX. Evaluación del Impacto del Cambio Climático en los Recursos Hídricos y Sequías en España; Ministerio de Agricultura, Alimentación y Medio Ambiente. Secretaría de Estado de Medio Ambiente. Dirección General del Agua. Gobierno de España: Madrid, Spain, 2017. Available online: http://publicacionesoficiales.boe.es/ escase (accessed on 16 January 2019).

23. Guttman, N.B. On the sensitivity of sample L moments to sample size. J. Clim. 1994, 7, 1026-1029. [CrossRef]

24. WMO. Standardized Precipitation Index User Guide (WMO-No. 1090); World Meteorological Organization: Geneva, Switzerland, 2012; p. 24.

25. WMO. Guide to Climatological Practices; World Meteorological Organization: Geneva, Switzerland, 2018.

26. Tsakiris, G. Drought Risk Assessment and Management. Water Resour. Manag. 2017, 31, 3083-3095. [CrossRef]

27. Estrela, T.; Sancho, T.A. Drought management policies in Spain and the European Union: From traditional emergency actions to Drought Management Plans. Water Policy 2016, 18, 153-176. [CrossRef]

28. Mckee, T.B.; Doesken, N.J.; Kleist, J. The Relationship of Drought Frequency and Duration to Time Scales. Available online: https://climate.colostate.edu/pdfs/relationshipofdroughtfrequency.pdf (accessed on 16 January 2019).

29. SAIH. Automatic Hydrological Information System (SAIH). Historical Hydrological Information-Guadalquivir River Basin. 2019. Available online: http://www.chguadalquivir.es/saih/ (accessed on 15 January 2019).

30. Bryan, K.; Ward, S.; Barr, S.; Butler, D. Coping with Drought: Perceptions, Intentions and Decision-Stages of South West England Households. Water Resour. Manag. 2019, 33, 1-18. [CrossRef]

31. Tayyab, M.; Ahmad, I.; Sun, N.; Zhou, J.; Dong, X. Application of Integrated Artificial Neural Networks Based on Decomposition Methods to Predict Streamflow at Upper Indus Basin, Pakistan. Atmosphere 2018, 9 , 494. [CrossRef]

32. Myronidis, D.; Ioannou, K.; Fotakis, D.; Dörflinger, G. Streamflow and Hydrological Drought Trend Analysis and Forecasting in Cyprus. Water Resour. Manag. 2018, 32, 1759-1776. [CrossRef] 